\title{
Descriptions of the mechanical behaviour of the Xigeda formation in Zhaizi village, Yunnan Province, China
}

\section{Xiaodong Fu ( $\nabla$ xdfu@whrsm.ac.cn )}

Wuhan Institute of Rock and Soil Mechanics Chinese Academy of Sciences

Yuxiang Du

State Key Laboratory of Blasting engineering, Jianghan University

Qian Sheng

Wuhan Institute of Rock and Soil Mechanics Chinese Academy of Sciences

\section{Research Article}

Keywords: Xigeda formation, mechanical behaviour, water, strength, damage constitutive model

Posted Date: March 30th, 2021

DOI: https://doi.org/10.21203/rs.3.rs-363681/v1

License: (c) This work is licensed under a Creative Commons Attribution 4.0 International License.

Read Full License 
1 Descriptions of the mechanical behaviour of the Xigeda formation in

2 Zhaizi village, Yunnan Province, China

3 Xiaodong $\mathrm{Fu}^{1,2^{*}}$, Yuxiang $\mathrm{Du}^{3,4}$, Qian Sheng ${ }^{1,2}$

4 (1 State Key Laboratory of Geomechanics and Geotechnical Engineering, Institute of Rock and Soil

5 Mechanics, Chinese Academy of Sciences, Wuhan 430071, China; 2 School of Engineering Science,

6 University of Chinese Academy of Sciences, Beijing 100049, China; 3 Hubei Key Laboratory of

7 Blasting Engineering, Jianghan University, Wuhan, Hubei 430056, China; 4 Hubei (Wuhan)

8 Institute of Explosion Science and Blasting Technology, Jianghan University, Wuhan, Hubei 430056,

9 China.)

10

$11 *$ Corresponding author: Xiaodong Fu, Corresponding author, xdfu@whrsm.ac.cn, +86 15827506700;

12 State Key Laboratory of Geomechanics and Geotechnical Engineering, Institute of Rock and Soil

13 Mechanics, Chinese Academy of Sciences, Wuhan 430071, China. https://orcid.org/0000-0002-0646147643.

15

16 


\section{Highlights}

18 1. Influence mechanisms of both the water content and the confining pressure on strength indexes

19 of Xigeda formation are discussed.

20 2. The statistical correlations between the shear strength index and the water content for Xigeda

21 formation, soft rock and soil are analyzed.

22 3. A damage constitutive model for the whole deformation process of Xigeda formation affected by 23 the water content is established and is proved by the test data.

24 
Abstract: The Xigeda formation is a set of Cenozoic lacustrine semi-rock discontinuously distributed in Southwest China. As a typical hard soil or soft/weak rock, the Xigeda formation causes problems when encountered in engineering practice due to its previously unknown mechanical behaviour. Typical samples taken from Zhaizi village along the Jinsha River have been studied. Influences of both the water content and the confining pressure on strength indices of the Xigeda formation were investigated by performing triaxial tests, and the statistical correlations between the shear strength index and the water content of the Xigeda formation, and its soft rock and soil are analysed. By introducing the tenets of the theory of damage mechanics, a damage constitutive model for the deformation of the Xigeda formation and the influence of the water content thereon was established. The results show that: (a) the peak strength, the cohesion and the friction angle decrease linearly with increasing water content; (b) the sensitivity of cohesion to water content is ranked (in ascending order) as: soft rock, the Xigeda formation, then soil, and the sensitivity of friction angle to water content is ranked (in ascending order) as: soil, the Xigeda formation, then soft rock; (c) the damage constitutive model requires few input variables, has a simple form, and can reflect the deformation and strength characteristics of the Xigeda formation under different confining pressures and water contents. The results provide a mechanism with which to understand and model (for both theoretical study and engineering application) the Xigeda formation.

Keywords: Xigeda formation; mechanical behaviour; water; strength; damage constitutive model.

\section{Introduction}

Many geological hazards have been induced by a type of geological materials classified as hard soils and soft/weak rocks (Cecconi and Viggiani, 2001; McCammon, 1999; Moon, 1993; Tommasi et al. 2014; Vaughan, 1993). These hard soils and soft/weak rocks include hard clays and clay-shales, soft sedimentary rocks, weak pyroclastic rocks such as tuffs, cemented coarse-grained materials such as weak sandstones, residuals soils, and very weathered hard rocks (Gens et al., 2005). The hard soils and soft/weak rocks have different structural and mechanical characteristics from rock and soil, and the water content exerts a significant influence on their strength; because the engineering classification and mechanical behaviour are not clear, these hard soils and soft/weak 
rocks have adverse effects in many practical cases (Abolmasov et al., 2014; Alonso and Pinyol, 2014; Barla et al., 1998; Di Maio et al., 2014; Margherita et al., 2018; Rotaru, 2011). This problem has aroused the common concern and attention of many in the geo-engineering community and among scholars. Four symposia/workshops, held in 1993 and 2011 in Athens, and 1998 and 2013 in Naples, had been hold under the banner "Geotechnics of Hard Soils-Weak Rocks" (Kanji, 2014; Luciano, 2015).

To define the hard soils and soft/weak rocks, several different classifications using strength have been proposed (BSI, 1981; IAEG, 1979; ISRM, 1982), but the upper and lower limits of soils and rocks differ due to different terms used. Using the uniaxial compressive strength for the upper limit and the undrained triaxial strength for the lower limit, Hawkins and Pinches (1992) proposed a classification for the entire range of soils and rocks, this classification acknowledges the continuum between soils and rocks, and Vaughan (1993) also suggested that soils and rocks should be regarded as continuously changing geological materials. At present, the boundary of the uniaxial compressive strength between the hard soil and the soft rock is recognised as being about $1 \mathrm{MPa}$ (Marinos, 1997), however, complete agreement remains to be reached (Johnston and Novello, 1993).

With the efforts of the geo-engineering community and various scholars, the mechanical behaviour of some typical hard soils and soft/weak rocks have been extensively investigated (Aversa and Evangelista, 1998; Clayton and Serratrice, 1993; Hornig and Klapperich, 2011; Shao, 1998; Sitarenios et al., 2011; Tatsuoka and Kohata, 1995). To describe the mechanical behaviour, constitutive models based on theories of elasticity, plasticity, and visco-plasticity, and micro-fracture and damage mechanics can be employed (Desai and Faruque, 1984; Gens and Nova, 1993). Gens et al. (2005) combined a framework used for soils with another intended for quasi-brittle materials and presented an elastoplastic constitutive law to reproduce a number of transitional behaviours in hard soils and soft rocks. Vukadin (2007) postulated a theoretical framework based on the observed similarity of the stress-strain behaviours for different materials ranging from soils to rocks and developed a model for hard soils and soft rocks named S_BRICK.

In the present work, a typical hard soil and soft/weak rock body known as the Xigeda formation distributed across Southwest China, was studied. The Xigeda formation is also called "Huntan formation", is named after Xigeda village in Hongge Township, Yanbian County, Panzhihua City, Sichuan Province by Yuan in 1958. This formation mainly includes fine-grained sandstone, clay, 
and conglomerate (Zhang, 2009). Scholars pointed out that water will weaken the physical and mechanical properties of the Xigeda formation, which may affect the stability of the geotechnical engineering works therein (Ling et al., 2015; Sun et al., 2012; Wang et al., 2018; Yang et al., 2020; Zhou et al., 2017). At present, In Southwest China, especially Yunnan and Sichuan, many large geotechnical projects are under construction or about to be built, and some of them are executed in the Xigeda formation. Thus, studies are warranted to have better understanding of the Xigeda formation. To investigate the mechanical behaviour of the Xigeda formation, samples thereof from Zhaizi village, Yunnan Province, China, have been studied. Section 2 presents the geological evolution and field investigation of the Xigeda formation. Section 3 describes the mechanical behaviour of the Xigeda formation under different confining pressures and water contents. A damage constitutive model is introduced to describe the stress-strain behaviour in Section 4, and Section 5 proves the validity of the damage constitutive model using test data.

\section{Geological evolution and field investigation of the Xigeda formation}

At present, research into on geological evolution of the Xigeda formation mainly includes its mechanism of occurrence, age of the formation, and its distribution. Previous studies attributed the occurrence of the Xigeda formation to either large-scale glacier development in the Pliocene or tectonic deformation that formed a series of lakes, where the barrier lake deposition can explain the dispersion of the Xigeda formation in plane and elevation (Li et al., 2012; Quaternary Glacier Survey Group, 1977). Based on the studies of the Xigeda formation in different sites, such as at Xichang City, Luding City, Panzhihua City, etc., the formation occurred at about 1.0 Ma 4.2 Ma, which is between the Pliocene of the tertiary system and the Pleistocene of the quaternary system (Kong et al., 2012; Xu and Liu, 2011). In Southwest China, the Xigeda formation is spread from Songpan County of Sichuan Province in the north to Zhaizi village of Yunnan Province in the south, and it is mainly distributed in bands and flakes with an area of $2.1 \times 10^{5} \mathrm{~km}^{2}$. As shown in Figure1, as a set of river-lake facies sediments in quiet water, the Xigeda formation can be found in the valleys of many watersheds, such as the Jinsha River, the Yalong River, the Dadu River, the Min River, etc., in western Sichuan Province and northern Yunnan Province. In different sites, the extent of diagenesis of the Xigeda formation may be different. Due to the insufficient compaction and 
114 generally smaller than that of the rock, thus the Xigeda formation has the characteristics of rock-

115 like non-rock and soil-like non-soil, and the geologists called it semi-rock (Liu and Nie, 2014).

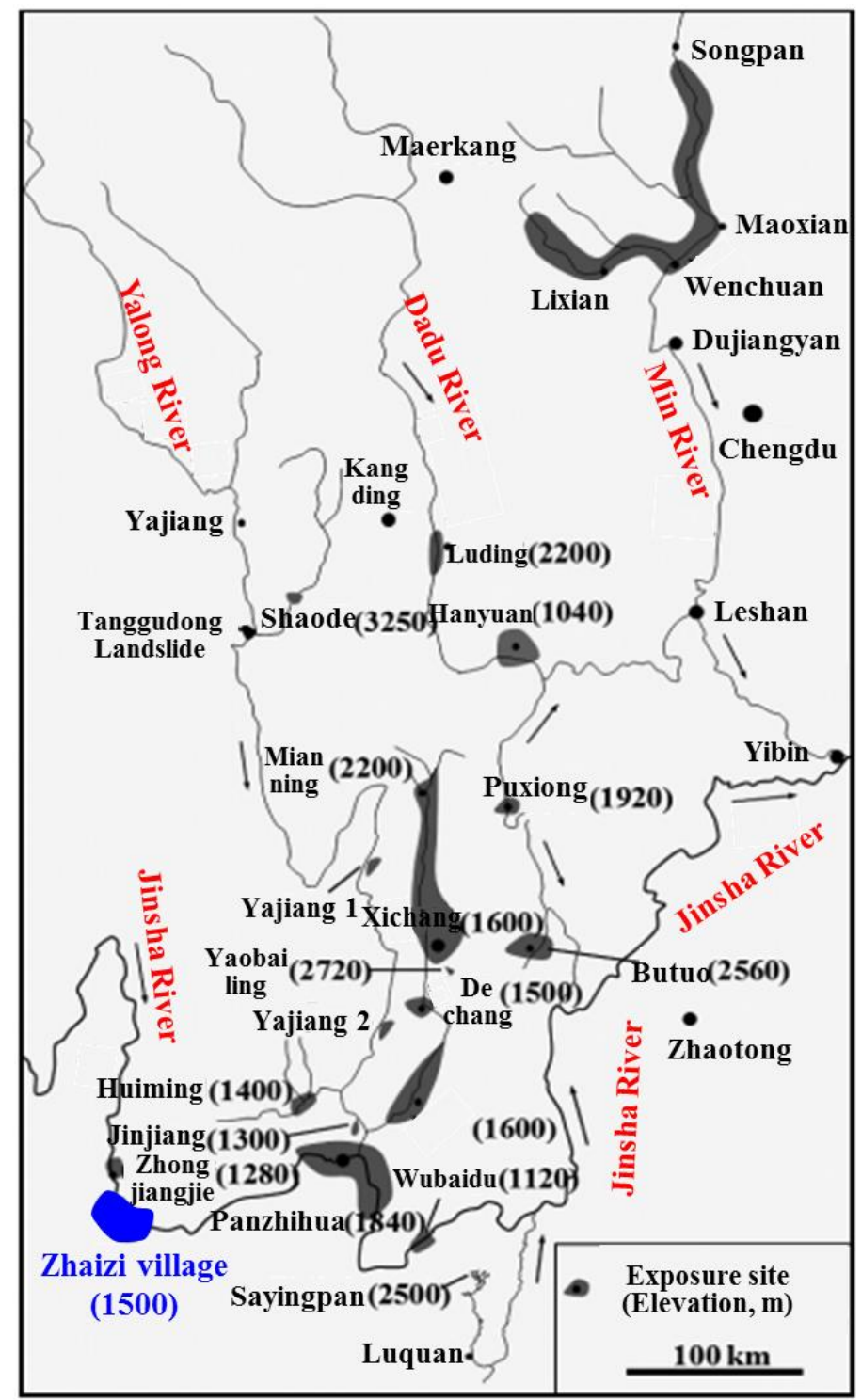

Figure 1 Distribution of the Xigeda formation. Modified from Xu and Liu (2011).

As shown in Figure 2, the Xigeda formation has an obvious horizontal bedding structure, mainly composed of clay, silt, and silty fine sand (Xu, 2011). The Xigeda formation in Zhaizi village along the Jinsha River is a typical deposit caused by a barrier lake. During the construction of the Taoyuan Jinsha River suspension bridge, which forms a key part of the Dali-Yongsheng Expressway, the Xigeda formation is exposed in the foundation pit of the gravity anchorage of the suspension bridge.

The foundation pit is in Zhaizi village, Taoyuan Township, Yongsheng County, Lijiang City, Yunnan 
126 is located in the Southwest foundation pit, and the foundation pit is about several hundred metres

127 from the reservoir area of the Ludila Hydropower Station along the Jinsha River. The base elevation

128 of the foundation pit is $1229.462 \mathrm{~m}$, and the highest reservoir water level is 1223.0 to $1225.0 \mathrm{~m}$.

129 Figure 3(b) shows a photograph of in-situ sampling operations: the Xigeda formation is brown/light

130 yellow, medium dense, slightly wet, mainly composed of the weak cementation of silt and sand.

131

132

133

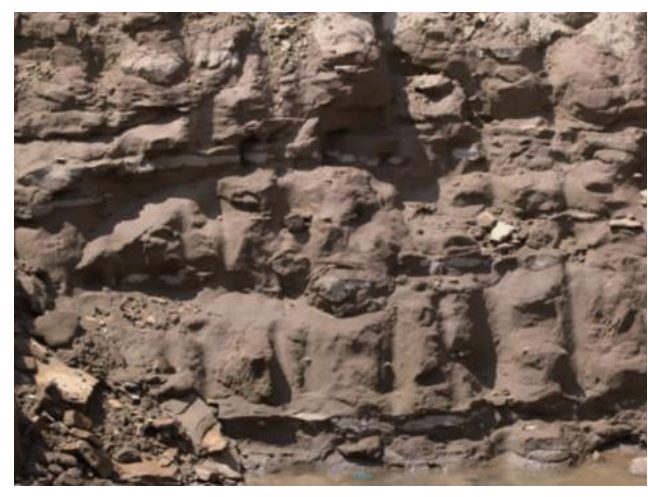

(a) Jingjiu Twonship of Sichuan Province (Xu, 2011)

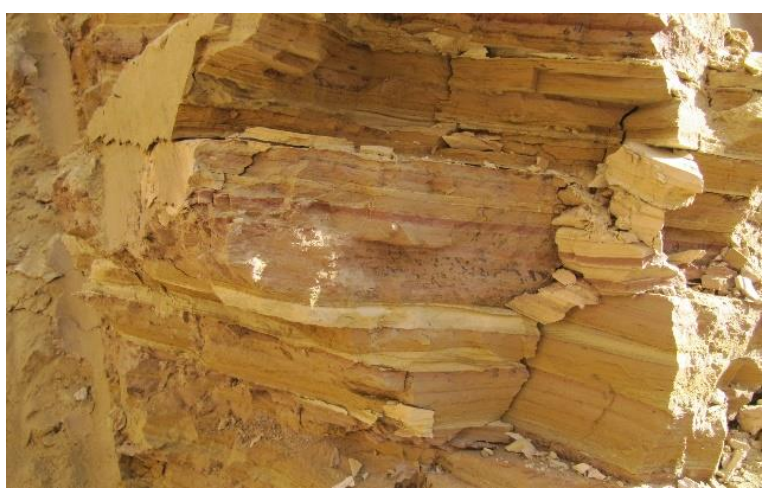

(b) Zhaizi village of Yunnan Province

Figure 2 Structural characteristics of the Xigeda formation.

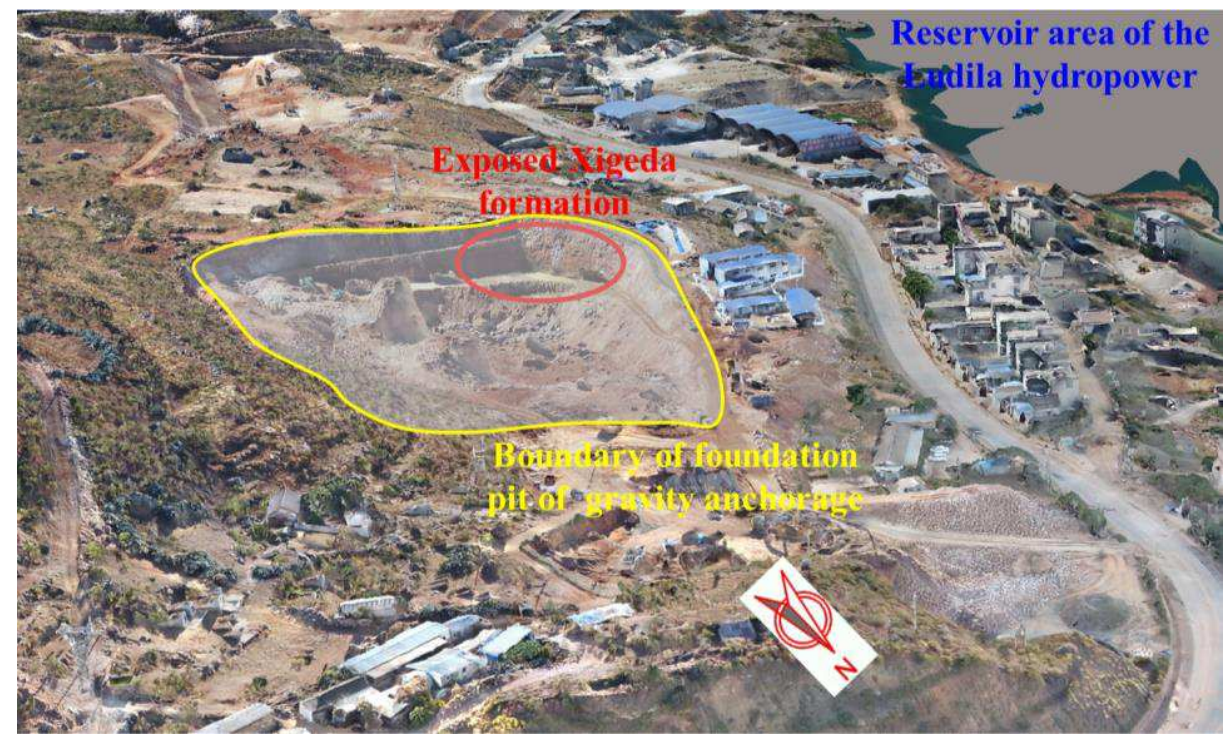

(a) The site photographed by a drone 

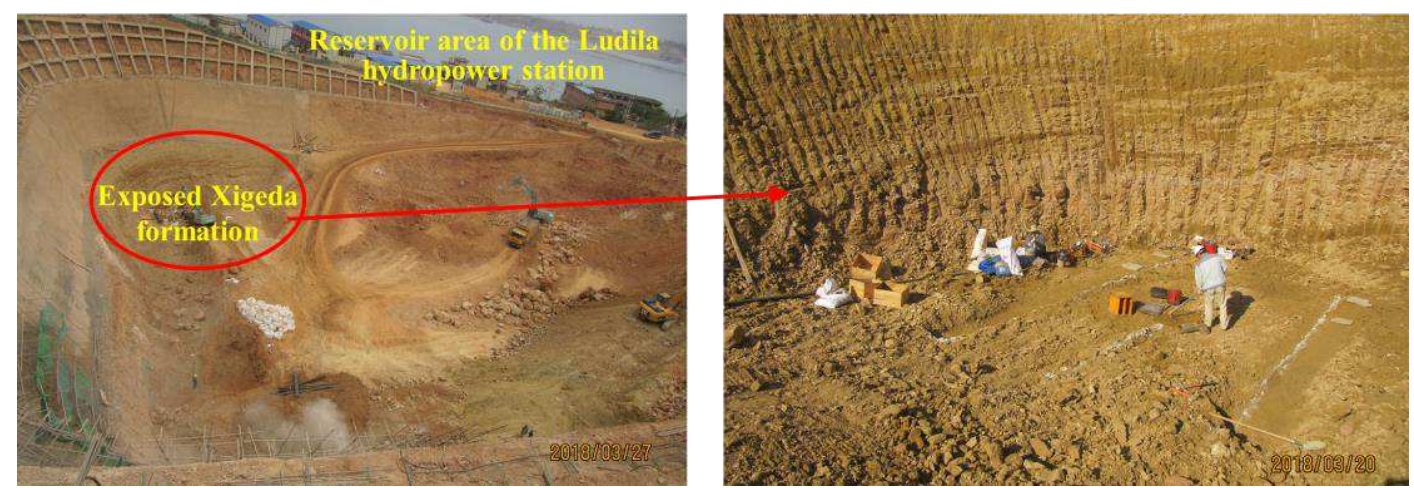

(b) Field sampling

Figure 3 Field investigation and sampling of the Xigeda formation exposed in a foundation pit.

\section{The mechanical behaviour of the Xigeda formation}

\subsection{Sample testing}

The X-ray diffraction tests show that the mineral composition of the Xigeda formation in Zhaizi village is mainly quartz $(31 \% \sim 51 \%)$, followed by clay minerals, including illite $(11 \% \sim 38 \%)$, montmorillonite $(8 \% \sim 9 \%)$, and clinochlore $(5 \% \sim 14 \%)$, in addition to a small amount of calcite (8\% 12\%), albite (0 12\%), and other minerals.

Using samples with diameter of $39.1 \mathrm{~mm}$ and a height of $80 \mathrm{~mm}$, a series of triaxial compression tests have been conducted to study the mechanical behaviour of the Xigeda formation. Five different gravimetric water contents $(17.79 \%, 20.58 \%, 24.86 \%, 26.52 \%$, and $30.83 \%)$ were used, wherein, the last represented a saturated sample and the others were obtained at different locations in the field. Figure 4 shows the typical samples at different water contents. At each water content, samples under four confining pressures $(200 \mathrm{kPa}, 400 \mathrm{kPa}, 600 \mathrm{kPa}$, and $800 \mathrm{kPa})$, were tested. The strengths and deformation indices under different water contents and confining pressures are listed in Table 1, respectively, where $\omega$ is the water content, $\sigma_{3}$ represents the confining pressure, $\sigma_{\mathrm{f}}$ is the peak strength, $E_{\mathrm{a}}$ is the average elastic modulus, $c$ denotes the cohesion, and $\varphi$ is the friction angle.
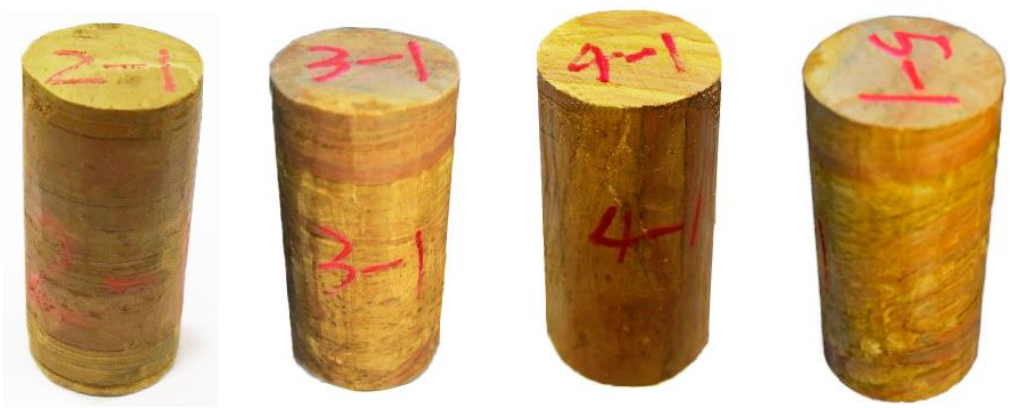
(c) $24.86 \%$

(d) $26.52 \%$

(e) $30.83 \%$

157 Figure 4 Samples with different water contents for triaxial compression testing.

158 Table 1 Strength and deformation indices at different water contents and confining pressures.

\begin{tabular}{|c|c|c|c|c|c|}
\hline$\omega / \%$ & $\sigma_{3} / \mathrm{kPa}$ & $\sigma_{\mathrm{f}} / \mathrm{kPa}$ & $E_{\mathrm{a}} / \mathrm{MPa}$ & $c / \mathrm{kPa}$ & $\varphi /\left(^{\circ}\right)$ \\
\hline \multirow{5}{*}{17.79} & 200 & 711.25 & 124.81 & \multirow{5}{*}{125.74} & \multirow{5}{*}{16.53} \\
\hline & 400 & 1012.8 & 107.84 & & \\
\hline & & & & & \\
\hline & 600 & 1453.42 & 123.04 & & \\
\hline & 800 & 1761.35 & 112.81 & & \\
\hline \multirow{4}{*}{20.58} & 200 & 639.21 & 77.43 & \multirow{4}{*}{119.77} & \multirow{4}{*}{14.57} \\
\hline & 400 & 961.2 & 83.50 & & \\
\hline & 600 & 1362.19 & 79.73 & & \\
\hline & 800 & 1620.19 & 87.48 & & \\
\hline \multirow{5}{*}{24.86} & 200 & 553.96 & 66.00 & \multirow{5}{*}{98.39} & \multirow{5}{*}{12.36} \\
\hline & 400 & 879.36 & 46.32 & & \\
\hline & & & & & \\
\hline & 600 & 1135.76 & 50.19 & & \\
\hline & 800 & 1498.16 & 68.41 & & \\
\hline \multirow{4}{*}{26.52} & 200 & 479.56 & 33.52 & \multirow{4}{*}{83.89} & \multirow{4}{*}{8.96} \\
\hline & 400 & 720.32 & 37.21 & & \\
\hline & 600 & 1036.09 & 40.86 & & \\
\hline & 800 & 1286.86 & 47.14 & & \\
\hline \multirow{5}{*}{30.83} & 200 & 358.41 & 15.95 & \multirow{5}{*}{55.43} & \multirow{5}{*}{5.50} \\
\hline & 400 & 623.29 & 20.35 & & \\
\hline & & & & & \\
\hline & 600 & 834.16 & 24.03 & & \\
\hline & 800 & 1096.04 & 34.32 & & \\
\hline
\end{tabular}

\subsection{Strength indices}

161 Figure 5 shows the relationship between the peak strength and the confining pressure: the results

162 follow the Mohr-Coulomb criterion. At different water contents, the peak strengths of Xigeda 163 formation materials increase with confining pressures. For example, when the water content is 
$16417.9 \%$, as the confining pressure is increased from $200 \mathrm{kPa}$ to $800 \mathrm{kPa}$, the peak strength increases

165 from $711 \mathrm{kPa}$ to $1761 \mathrm{kPa}$.

166 Figure 6 illustrates the relationship between the peak strength and the water content, and the results

167 illustrate that the peak strengths decrease linearly with increasing water content. For example, when

168 the confining pressure is $200 \mathrm{kPa}$, and the water content is increased from $17.79 \%$ to $30.83 \%$, the

169 peak strength decreases from $711 \mathrm{kPa}$ to $358 \mathrm{kPa}$.

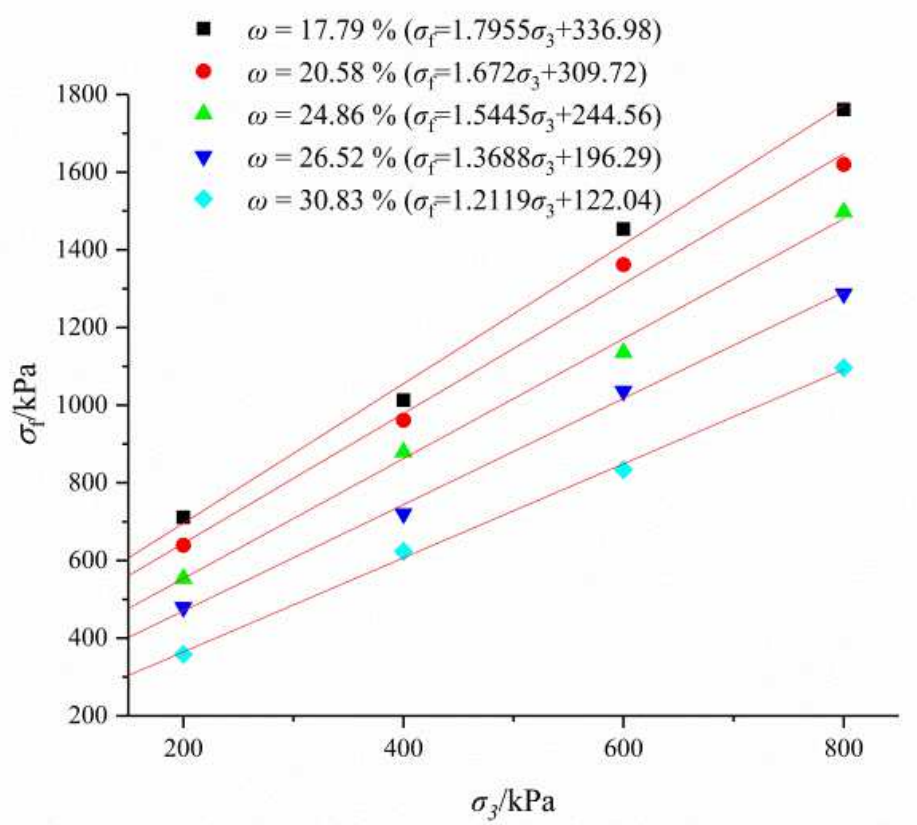

170

171 Figure 5 Relationship between peak strength and confining pressure.

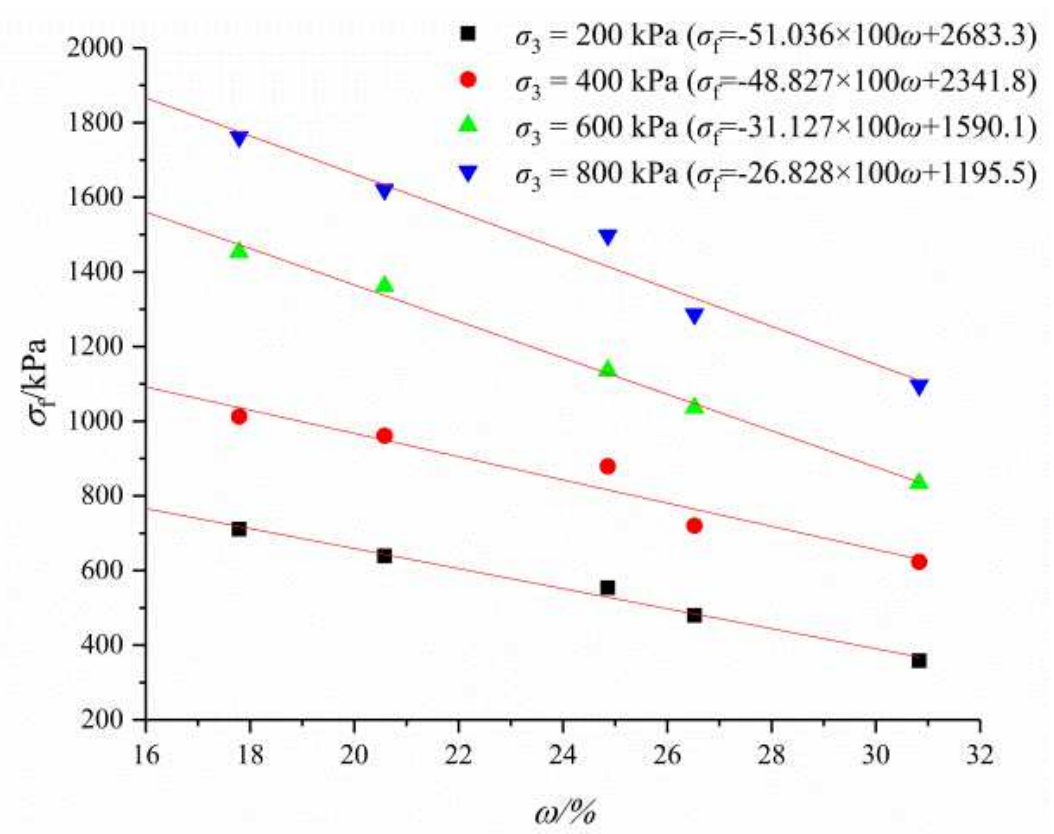

Figure 6 Relationship between peak strength and water content. 
175 Figure 7 shows the relationship between cohesion and friction angle of the Xigeda formation and 176 the water content, the results illustrate that both the cohesion and friction angle decrease linearly 177 with increasing water content. When the water content is increased from $17.79 \%$ to $30.83 \%$, the cohesion decreases from $126 \mathrm{kPa}$ to $55 \mathrm{kPa}$, and the friction angle decreases from $16.53^{\circ}$ to $5.5^{\circ}$.

179 From the micro-scale perspective, the reasons for this can be considered as follows: the influence of water content on cohesion is mainly due to the chemical reaction of water with illite and montmorillonite. Absorption of the water molecules leads to the increase of the clay aggregate volume, resulting in swelling, and the cemented structure is destroyed. The influence of water content on friction angle is mainly attributed to the effect of the water film formed between the particles under the action of molecular forces, which rounds the surfaces of the particles, and lubricates them.

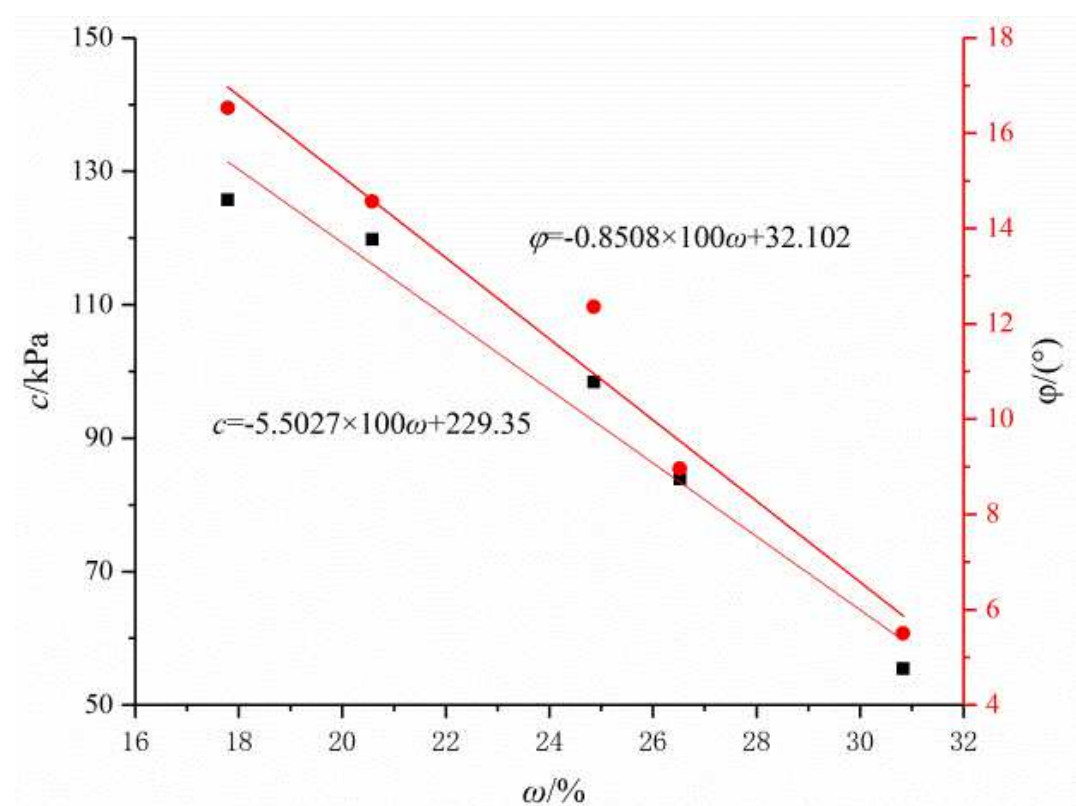

Figure 7 Relationship between cohesion, friction angle, and water content.

The relationships between the shear strength indices and the water contents of the Xigeda formation samples taken from six locations (nine soils and eight soft rocks) were investigated (Huang et al., 2005; Wen et al., 2005; Zhang et al., 2011; Zhou et al., 2014). Figure 8 shows the relationship between the cohesion and the water content. The results show that the cohesion of such geotechnical materials decrease with increasing water contents, and the sensitivity of cohesion to water content is ranked (in ascending order) as: soft rock, the Xigeda formation, then soil. According to the range 
of distribution of cohesion and water content, nine regions are used to characterise the formation.

196 The soft rock is mainly distributed in region (1), the Xigeda formation is mainly distributed in

197 regions (4) and (5), and the soil is mainly distributed in regions (4), (5), (7), (8), and (9), which

198 indicate that the main distribution of cohesion and water content is as follows: $0.2 \sim 20 \mathrm{MPa}$ and $\omega$ $<17 \%$ for soft rock, 30 200 kPa and $\omega<40 \%$ for the Xigeda formation, and $2 \sim 200 \mathrm{kPa}$ and $\omega<$ $50 \%$ for soil. Figure 9 shows the relationship between the friction angle and the water content. The results show that the friction angles of these geotechnical materials decrease with increasing water content, the distributions have no obvious boundaries, and the sensitivity of friction angle to water content is ranked (in ascending order) as: soil, the Xigeda formation, then soft rock. The statistical correlation between the shear strength index and the water content reflects that the strength indicates that the Xigeda formation is a special kind of geotechnical material somewhere between soil and soft rock.

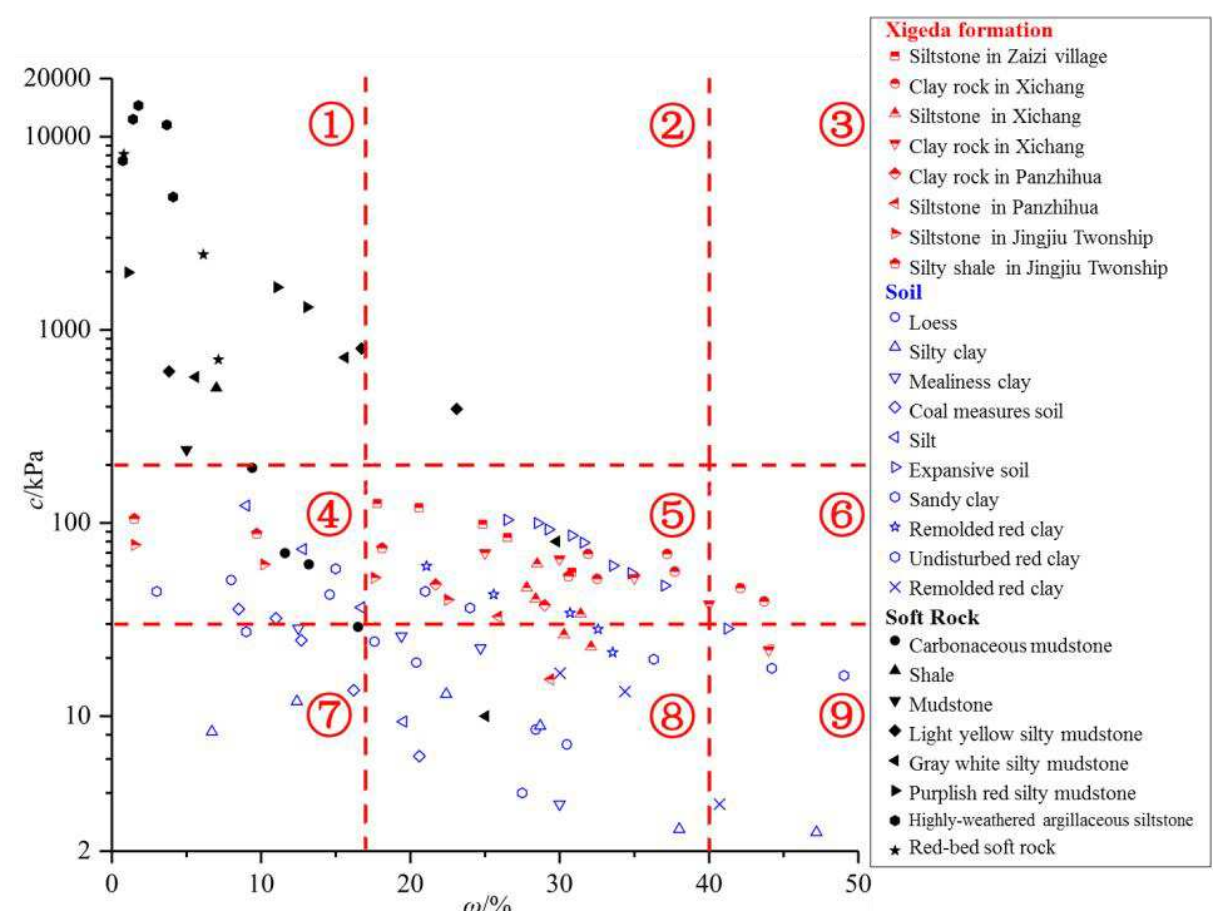

Figure 8 Relationship between cohesion and water content: the Xigeda formation, soil. and soft rock. 


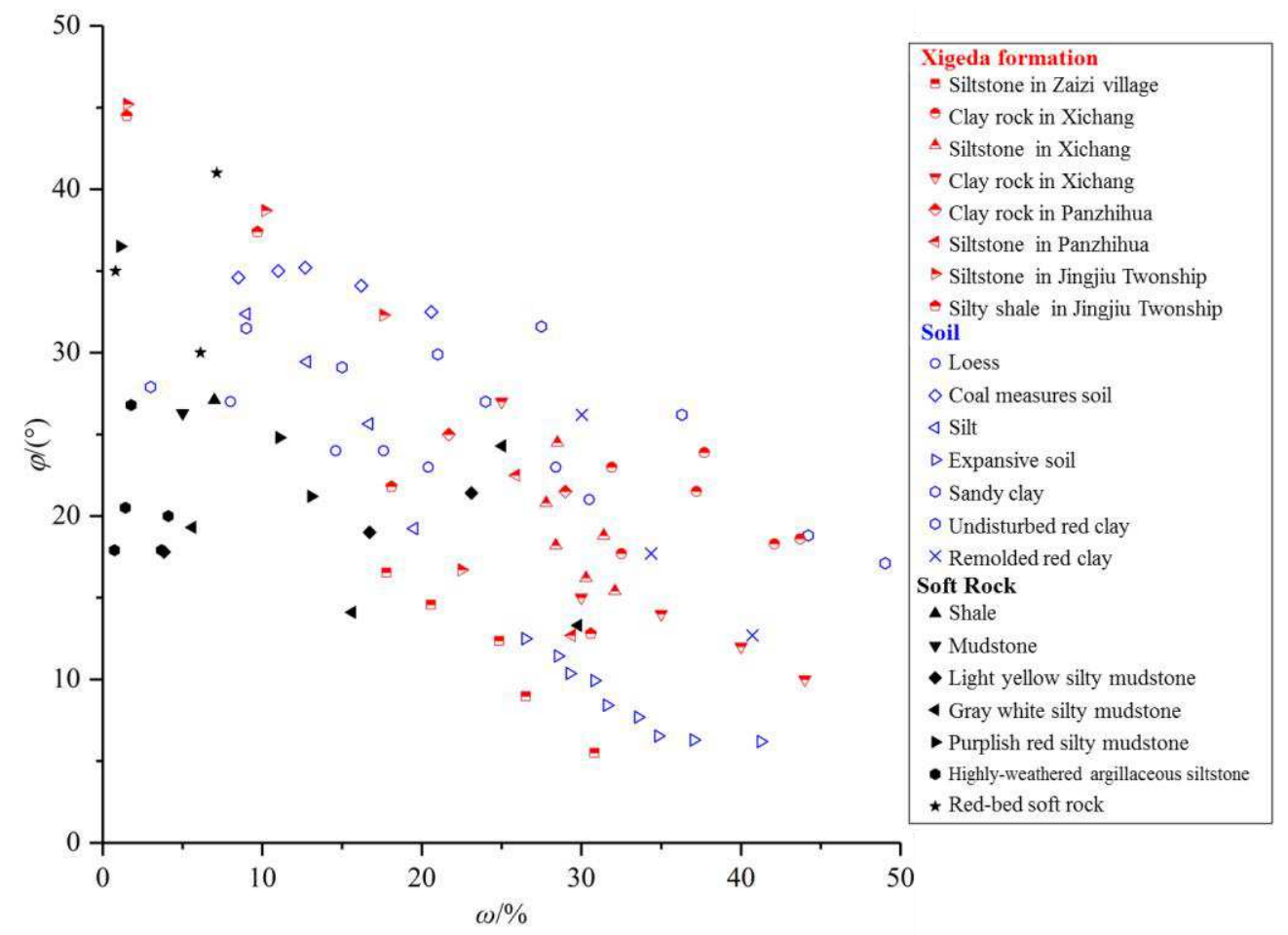

211 Figure 9 Relationship between friction angle and water content: the Xigeda formation, soil, and soft rock.

\section{A damage constitutive model}

\subsection{Introduction to the damage constitutive model}

215 Under the actions of external forces, the fractures of geotechnical materials continuously propagate, and this process presents a complex stress-strain relationship and is irreversible (Desai, 2005). Using the principle of irreversible thermodynamics and the continuum mechanics, Lemaitre (1984) established the theory of damage mechanics, which allows assessment of the evolution of damage in many materials, and is appropriate to describe the mechanical behaviour of geotechnical materials. The key of damage mechanics is to establish a reasonable damage model. Some mechanical models for quasi-brittle materials such as rock and concrete have been established (e.g., the Krajcinovie damage model (1982) and Frantzikonis damage model (1987)). These models divide the stressstrain curve into several segments, assume the segments have different mechanical properties, and the modelled constitutive curves are consistent with the experimental results. In addition, Cao et al. $(1998,2010)$ studied the deformation of rock by combining mesoscopic damage mechanics with mathematical statistics, and this approach uses statistical variation of rock properties at a small scale to generate realistic behaviour at a larger scale. 
229 (Lemaitre, 1984),

$$
\begin{gathered}
D_{\mathrm{n}}=\frac{S-\xi / c}{S} \\
\& / \epsilon \frac{\sigma}{1-D} \\
\varepsilon=\& / p E=\frac{\sigma}{(1-D) E} \\
\sigma=(1-D) E \varepsilon
\end{gathered}
$$

230

231

where, $D_{\mathrm{n}}$ represents the damage variable on the cross-section with normal direction $n, D$ is the damage variable of isotropic material, $S$ is the apparent cross-sectional area, $\$ t$ is the effective cross-sectional area, $d t$ is the effective stress tensor, $\sigma$ is the total stress tensor, $\varepsilon$ is the strain tensor, $E$ is the elastic modulus. $D=0$ indicates the undamaged state, while $D=1$ means the damaged part of the material has no bearing capacity, which is unrealistic. To address this problem, Shen (1993) and Cao (2012) developed a new damage model for geotechnical materials under triaxial compression conditions,

$$
\sigma_{1}=(1-D) \sigma_{1}^{\prime}+D \sigma_{\mathrm{r}}
$$

where, $\sigma_{1}^{\prime}$ is the axial effective stress, $\sigma_{\mathrm{r}}$ is the residual strength. The new damage model can reflect the fact that residual strength does not change with deformation in the process of strain softening of geotechnical materials, but two assumptions should be satisfied. The first assumption is that the material damage only occurs in the cross-section whose normal direction is the axial direction, the cross-section whose normal direction is the lateral direction is always in an undamaged state during the loading process. The second assumption is that the stress-strain relationship of the undamaged part of the material obeys Hooke's law.

\subsection{Determination of the model parameters}

To use the new damage model to describe of the mechanical behaviour of the Xigeda formation, it is necessary to determine the model parameters in formula (5). According to the hypothesis of strain equivalence, under triaxial compression,

$$
\varepsilon_{1}^{\prime}=\varepsilon_{\mathrm{r}}=\varepsilon_{1}
$$

According to the first assumption of the new damage model, 


$$
\begin{aligned}
& \sigma_{2}^{\prime}=\sigma_{2} \\
& \sigma_{3}^{\prime}=\sigma_{3}
\end{aligned}
$$

According to the second assumption of the new damage model, and in combination with formulae (6) to (8), $\sigma_{1}^{\prime}$ can be obtained,

$$
\sigma_{1}^{\prime}=E \varepsilon_{1}^{\prime}+\mu\left(\sigma_{2}^{\prime}+\sigma_{3}^{\prime}\right)=E \varepsilon_{1}+\mu\left(\sigma_{2}+\sigma_{3}\right)
$$

where $\mu$ is the Poisson's ratio. The residual strength of the Xigeda formation satisfies the MohrCoulomb criterion, and $\sigma_{\mathrm{r}}$ can be obtained thus,

$$
\sigma_{\mathrm{r}}=\frac{\left(1+\sin \varphi_{\mathrm{r}}\right) \sigma_{3}+2 c_{\mathrm{r}} \cos \varphi_{\mathrm{r}}}{1-\sin \varphi_{\mathrm{r}}}
$$

where $c$ and $\varphi$ are the cohesion and friction angle, respectively, and the subscript $\mathrm{r}$ represents the residual value. Combining formulae (5), (9), and (10),

$$
\sigma_{1}=(1-D) E \varepsilon_{1}+\mu\left(\sigma_{2}+\sigma_{3}\right)+D B
$$

where,

$$
B=\frac{\left(1+\sin \varphi_{\mathrm{r}}\right) \sigma_{3}+2 c_{\mathrm{r}} \cos \varphi_{\mathrm{r}}}{1-\sin \varphi_{\mathrm{r}}}-\mu\left(\sigma_{2}+\sigma_{3}\right)
$$

To establish the relationship between damage variable $D$ and stress-strain, the mesoscopic element strength is introduced (Tang et al. 1993). The mesoscopic element strength $F$ reflects the risk of failure of a mesoscopic element.

In the triaxial test, the confining pressure remains unchanged, and the accumulation of the axial effective stress increment of the undamaged part of the material can reflect the risk of failure of the geotechnical material. Thus, the accumulation of the axial effective stress increment in the undamaged part of the material is taken as the mesoscopic element strength. The differential form of formula (9) is as follows,

$$
\mathrm{d} \sigma_{1}^{\prime}=E \mathrm{~d} \varepsilon_{1}+\mu\left(\mathrm{d} \sigma_{2}+\mathrm{d} \sigma_{3}\right)
$$

During the axial loading process, $\mathrm{d} \sigma_{2}=\mathrm{d} \sigma_{3}=0$, and it is assumed that $\varepsilon_{1}=0$ is the initial state, the mesoscopic element strength can be obtained thus,

$$
F=\int \mathrm{d} \sigma_{1}^{\prime}=E \int \mathrm{d} \varepsilon_{1}=E \varepsilon_{1}
$$

It is assumed that the mesoscopic element strength follows a Weibull distribution, and the damage variable can be obtained by integrating its probability density function (Tang et al. 1993), 


$$
D=1-\exp \left[-\left(F / F_{0}\right)^{\mathrm{m}}\right]
$$

where $F_{0}$ and $m$ are the distribution parameters pertaining to mesoscopic element strength. $F_{0}$ and $m$ can be determined according to the extremum characteristics of the peak strength of triaxial test. The peak strength of triaxial test of geotechnical materials is $\sigma_{\mathrm{f}}$, and the corresponding strain is $\varepsilon_{\mathrm{f}}$, then

$$
\left.\frac{\partial \sigma_{1}}{\partial \varepsilon_{1}}\right|_{\sigma_{1}=\sigma_{\mathrm{f}}, \varepsilon_{1}=\varepsilon_{\mathrm{f}}}=0
$$

From the partial differentiation of formula (11), it can be concluded that,

$$
\frac{\partial \sigma_{1}}{\partial \varepsilon_{1}}=(1-D) E+\left(B-E \varepsilon_{1}\right) \frac{\partial D}{\partial \varepsilon_{1}}
$$

Combining formulae (14) and (15), it can be obtained that,

$$
\frac{\partial D}{\partial \varepsilon_{1}}=E \exp \left[-\left(\frac{F}{F_{0}}\right)^{m}\right]\left[m\left(\frac{F}{F_{0}}\right)^{m-1}\right] \frac{1}{F_{0}}
$$

Combining formulae (16) to (18), it can be obtained that,

$$
\begin{aligned}
& m=\frac{F_{\mathrm{f}}}{\left(B-E \varepsilon_{\mathrm{f}}\right) \ln \left(1-D_{\mathrm{f}}\right)} \\
& F_{0}=F_{\mathrm{f}}\left[-\ln \left(1-D_{\mathrm{f}}\right)\right]^{-1 / m}
\end{aligned}
$$

where $F_{\mathrm{f}}$ is the mesoscopic element strength when $\sigma_{1}=\sigma_{\mathrm{f}}, D_{\mathrm{f}}$ is the damage variable when $\sigma_{1}=\sigma_{\mathrm{f}}$, and formula (14) can be written as

$$
F_{\mathrm{f}}=E \varepsilon_{\mathrm{f}}
$$

Substituting $\sigma_{1}=\sigma_{\mathrm{f}}$ and $\varepsilon_{1}=\varepsilon_{\mathrm{f}}$ into formula (11),

$$
D_{\mathrm{f}}=\frac{\sigma_{\mathrm{f}}-E \varepsilon_{\mathrm{f}}-\mu\left(\sigma_{2}+\sigma_{3}\right)}{B-E \sigma_{3}}
$$

The peak strength of the material comprising the Xigeda formation satisfies the Mohr-Coulomb criterion,

$$
\sigma_{\mathrm{f}}=\frac{\left(1+\sin \varphi_{\mathrm{f}}\right) \sigma_{3}+2 c_{\mathrm{f}} \cos \varphi_{\mathrm{f}}}{1-\sin \varphi_{\mathrm{f}}}
$$

281 where the subscript $\mathrm{f}$ represents the peak value. Based on the triaxial test results of samples taken

282 from the Xigeda formation, it is assumed that there is a linear relationship among the axial strain corresponding to peak strength $\varepsilon_{\mathrm{f}}$, the confining pressure, and the water content,

$$
\varepsilon_{\mathrm{f}}=\frac{a+b \sigma_{3}+c\left(\omega-\omega_{50}\right)}{100}
$$


where $a, b$, and $c$ are constants, which can be obtained by least squares regression of test data.

Table 2 presents the axial strains corresponding to peak strengths of the test data, $a=0.6422$, $b=1.088 \times 10^{-3} \mathrm{kPa}^{-1}$, and $c=8.078 \times 10^{-2}$.

By substituting formulae (21) to (24) into formulae (19) and (20), $m$ and $F_{0}$ can be obtained. Then, formulae (19) and (20) can be substituted into formula (15), and the functional expression of the damage variable can be obtained. Finally, by substituting the damage variable into formula (11), a damage constitutive model for the whole deformation process of material in the Xigeda formation, as affected by water content, is constructed.

Table 2 Axial strain corresponding to peak strength.

\begin{tabular}{ccccc}
\hline \multirow{2}{*}{$\omega / \%$} & \multicolumn{5}{c}{$\varepsilon_{\mathrm{f}} / \%$} \\
\cline { 2 - 5 } & $\sigma_{3}=200 \mathrm{kPa}$ & $\sigma_{3}=400 \mathrm{kPa}$ & $\sigma_{3}=600 \mathrm{kPa}$ & $\sigma_{3}=800 \mathrm{kPa}$ \\
\hline 17.79 & 1.03 & 1.22 & 1.41 & 1.58 \\
20.58 & 1.31 & 1.49 & 1.75 & 1.99 \\
24.86 & 1.56 & 1.74 & 1.93 & 2.19 \\
26.52 & 1.78 & 2.01 & 2.23 & 2.39 \\
30.83 & 2 & 2.25 & 2.52 & 2.78 \\
\hline
\end{tabular}

\section{Validation of the damage constitutive model}

The deformation parameters of the Xigeda formation obtained from the mechanical tests are as follows, $E=120 \mathrm{MPa}$ and $\mu=0.26$. At water contents of $17.79 \%, 20.58 \%, 24.86 \%, 26.52 \%$, and $30.83 \%$, and confining pressures of $200 \mathrm{kPa}, 400 \mathrm{kPa}, 600 \mathrm{kPa}$, and $800 \mathrm{kPa}$, the whole deformation processes of the Xigeda formation under different conditions is revealed. Figures 10 and 11 show comparisons of the test data and the model results.

The comparisons indicate that the damage constitutive model can reflect the variation of strength under different confining pressures and water contents. The peak strength and residual strength increase with the confining pressure, the peak strength decreases significantly with increasing water content, and the residual strength decreases to a lesser extent with increasing water content, which is consistent with the variation seen in test data. The comparisons also indicate that the damage constitutive model can reflect the variation of 

to the peak strength increases with both confining pressure and water content. In the softening stage,

308 the stress decreases with increasing water content. At a low water content, after reaching the peak 309 strength, the stress decreases rapidly to the residual strength, and the strain softening characteristics 310 are obvious, which reflect the characteristics of the rock in the Xigeda formation. When the water 311 content is close to that at saturation, the rate of change of stress after reaching the peak strength is 312 low, and the difference between the peak and residual strengths is small, suggesting that strain313 softening is less obvious, reflecting the soil-like characteristics of the Xigeda formation.

314

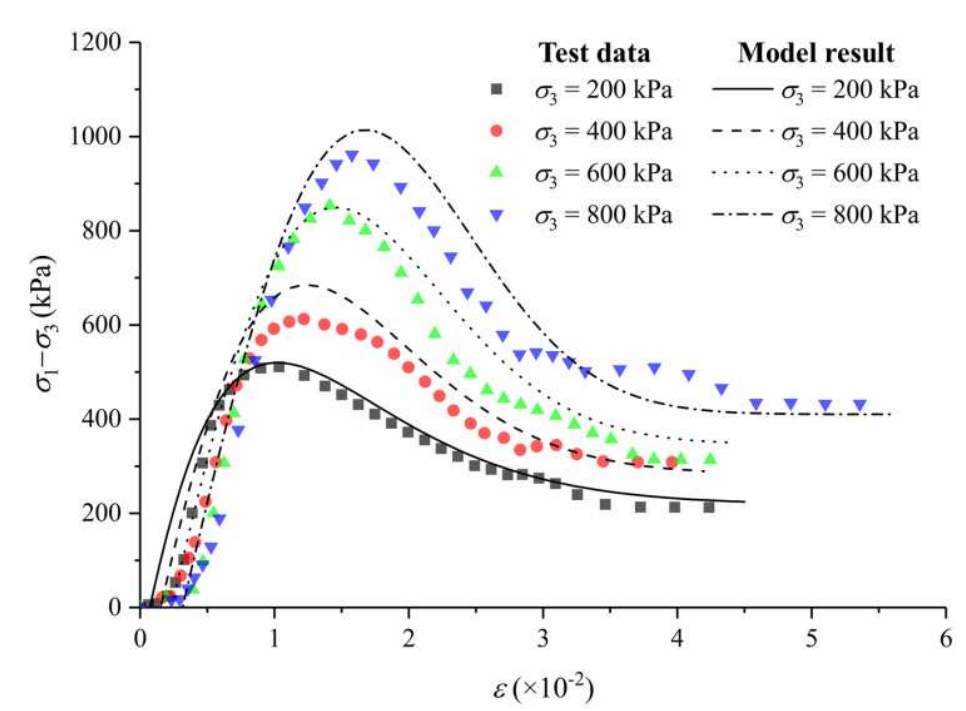

(a) $\omega=17.79 \%$

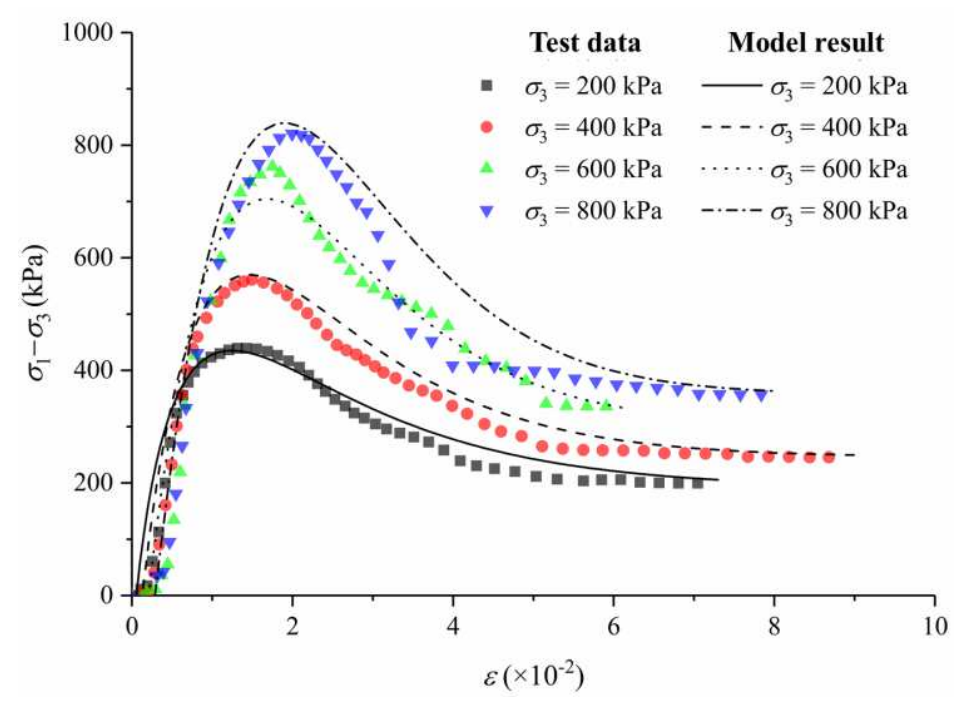

(b) $\omega=20.58 \%$ 


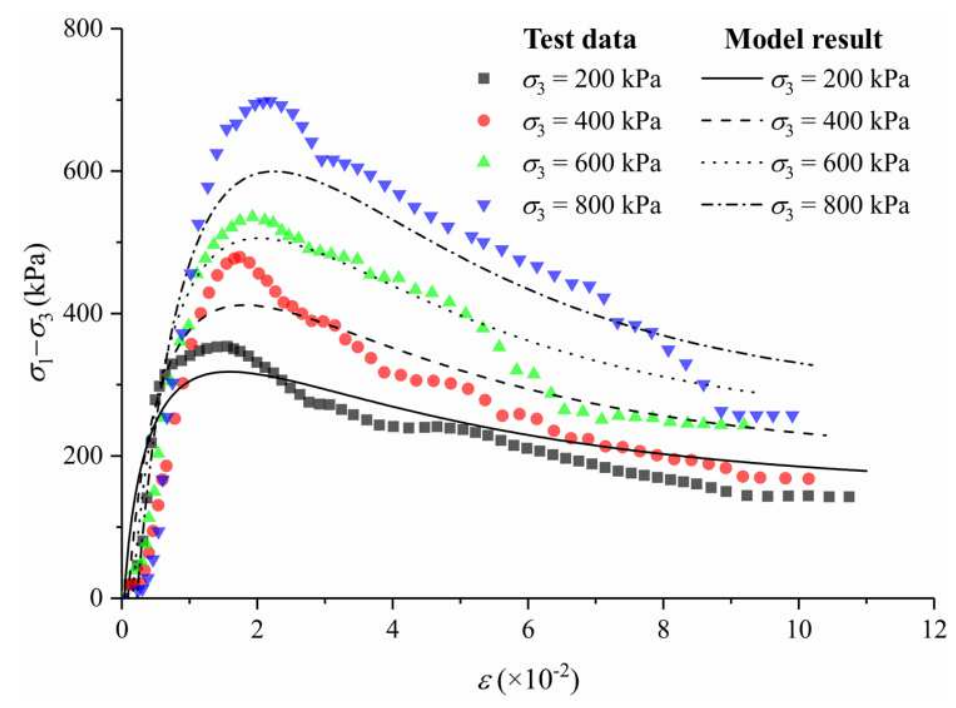

(c) $\omega=24.86 \%$

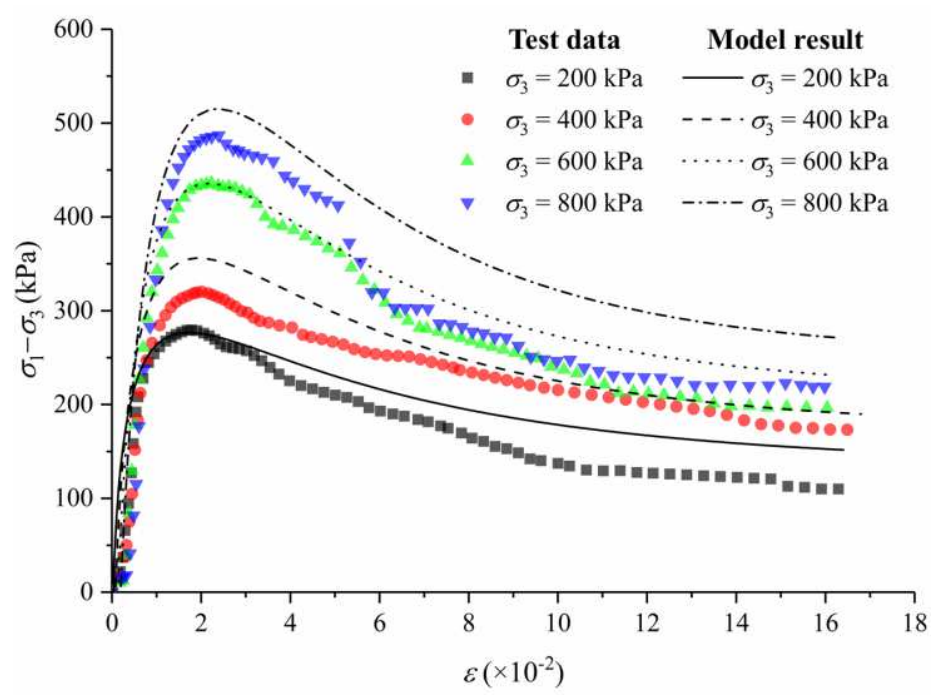

(d) $\quad \omega=26.52 \%$

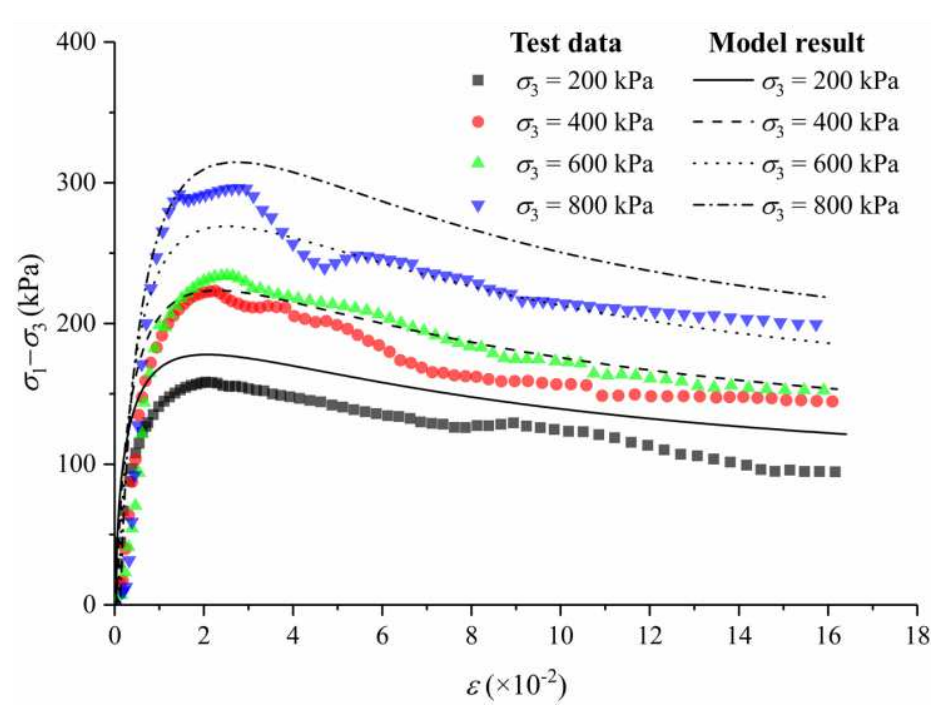

(e) $\omega=30.83 \%$

324 Figure 10 Comparisons of test data and model results at different water contents. 


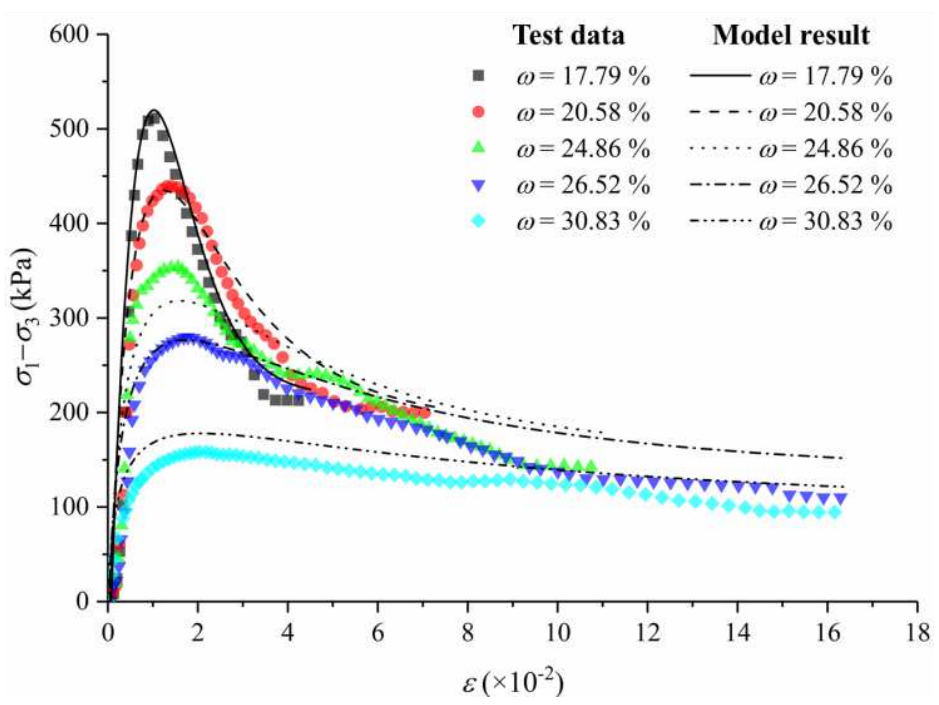

326

(a) $\sigma_{3}=200 \mathrm{kPa}$

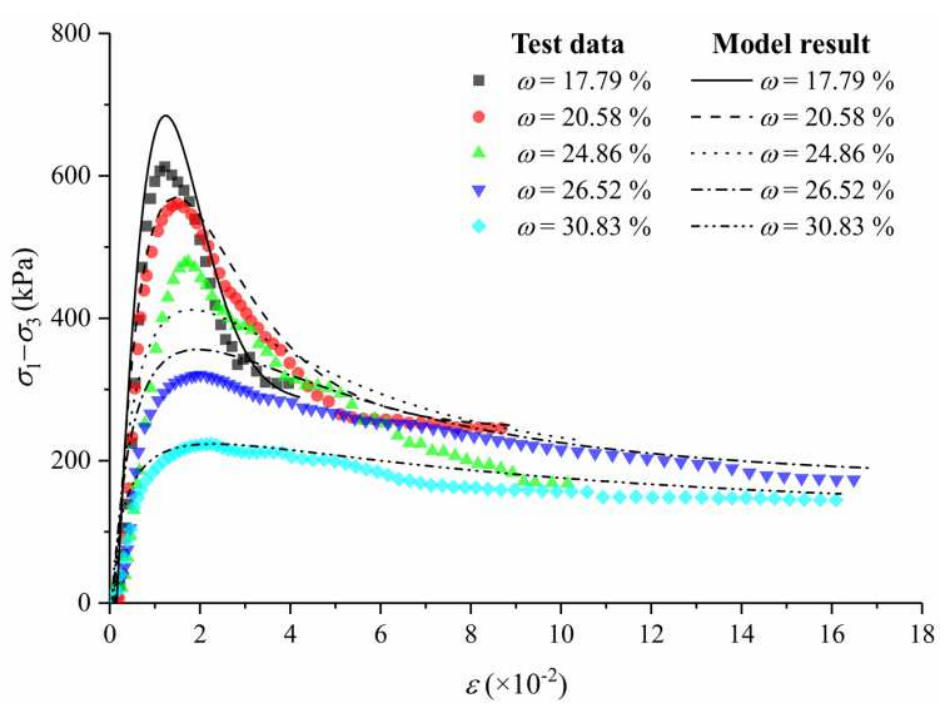

(b) $\sigma_{3}=400 \mathrm{kPa}$

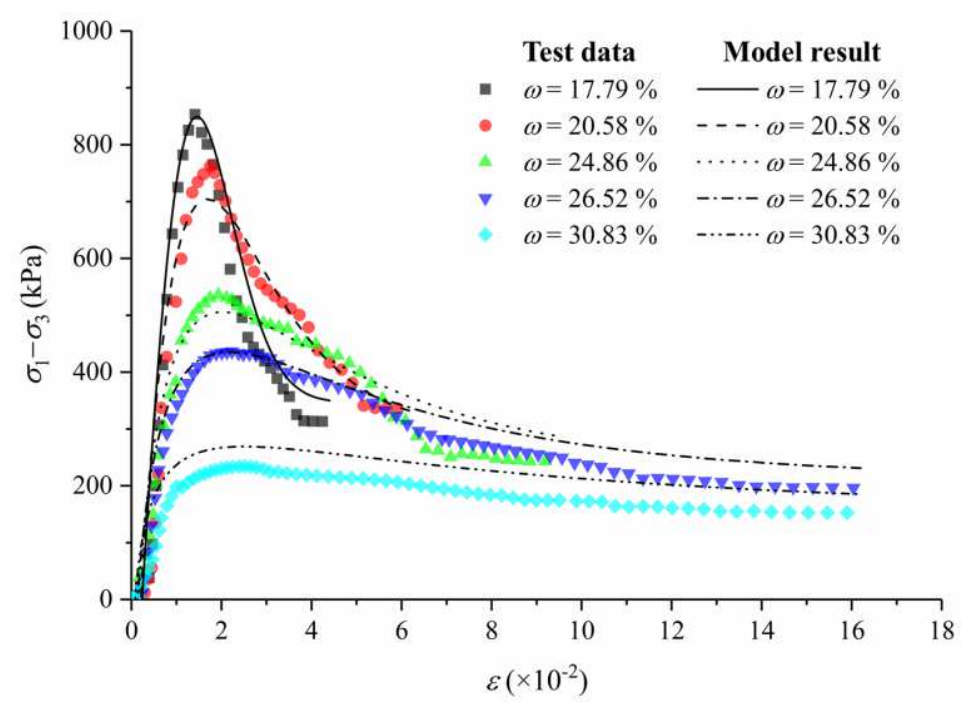

(c) $\sigma_{3}=600 \mathrm{kPa}$ 


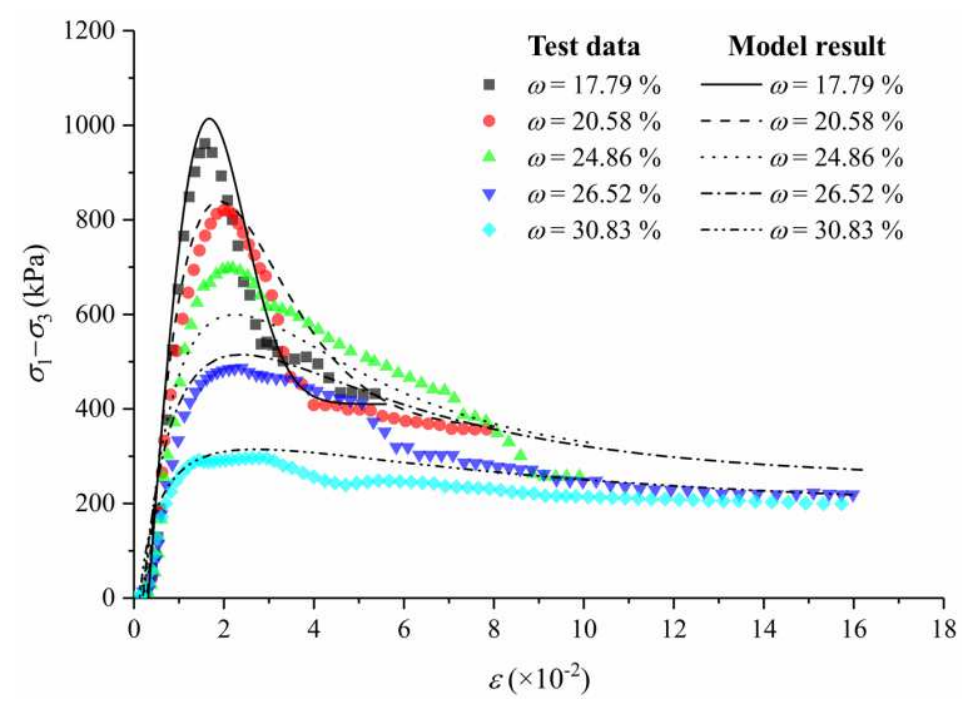

(d) $\sigma_{3}=800 \mathrm{kPa}$

333 Figure 11 Comparisons of test data and model results at different confining pressures.

\section{Conclusion}

The geological evolution and distribution characteristics of the Xigeda formation were investigated, by in-situ sampling of material from the Xigeda formation in Zhaizi village along the Jiasha River and triaxial tests were conducted at different gravimetric water contents. Using the test data, the influences of both the water content and the confining pressure on strength were assessed, a damage constitutive model for the whole deformation process of the Xigeda formation affected by water content was established. The main conclusions are as follows:

342 (a) The peak strength of material in the Xigeda formation increases linearly with the confining pressure, following the Mohr-Coulomb criterion. The peak strength, the cohesion, and the friction angle decrease linearly with increasing water contents. The microscopic mechanism can be considered as one in which that the hygroscopic expansion of illite and montmorillonite is generated, thus destroying the cemented structure therein and reducing the cohesion; the particle surface tends to become more rounded, and the friction angle decreases due to the lubricating effect of the water film.

349 (b) The statistical correlation between the shear strength index and the water content reflects the fact that the strength characteristics of the Xigeda formation differ from those of soil and soft rock. The cohesion and friction angle of soft rock, the Xigeda formation, and soil decrease with increasing 
water content; the sensitivity of cohesion to water content is ranked (in ascending order) as: soft rock, the Xigeda formation, the soil, and the sensitivity of friction angle to water content is ranked (in ascending order) as: soil, the Xigeda formation, then soft rock.

(c) The damage constitutive model can reflect the deformation process of material from the Xigeda formation under different confining pressures and water contents. The peak strength, residual strength, and axial strain corresponding to the peak strength calculated by the damage constitutive model agree with the test data. The form of the damage constitutive model is simple, and the input variables are few, thus the damage constitutive model of the Xigeda formation is convenient for wider engineering application.

\section{Data Availability}

Some or all data, models, or code that support the findings of this study are available from the corresponding author upon reasonable request.

\section{Acknowledgements}

The work reported in this paper is financially supported by the Youth Innovation Promotion Association CAS (No.2021325), the National Natural Science Foundation of China (No. 51779250), and the International Partnership Program of Chinese Academy of Sciences Grant No. 131551KYSB20180042.

\section{Conflict of interest}

The authors declared that they have no conflicts of interest to this work.

\section{References}

[1]. Abolmasov, B., Milenković, S., Marjanović, M., Đurić, U., Jelisavac, B., 2014. A geotechnical model of the Umka landslide with reference to landslides in weathered Neogene marls in Serbia. Landslides 12(4), 689-702.

[2]. Alonso, E.E., Pinyol, N.M., 2014. Slope stability in slightly fissured claystones and marls. Landslides 12(4), 643-656.

[3]. Aversa, S., Evangelista, A., 1998. The mechanical behaviour of a pyroclastic rock: yield strength and destructuration effects. Rock Mechanics and Rock Engineering 31(1), 25-42.

[4]. Barla, G., Barbero, M., Castelletto, M., Maderni, G., 1998. A case of plane shear slope instability during the severe rainfall event of 4-6 November 1994 in Piemonte (Italy). 2nd International Symposium on Hard Soils 
and Soft Rocks, Naples (Italy), 12-14 October 1998.

[5]. British Standard Institution BSI (1981). Code of practice for site investigation, BS 5930. HMSO, London.

[6]. Cao, W.G., 2012. A statistical damage simulation method for rock full deformation process with consideration of the deformation characteristics of residual strength phase. China Civil Engineering Journal (6), 139-145.(in Chinese with English Abstract)

[7]. Cao, W.G., Fang, Z.L., Tang, X.J., 1998. A study of statistical constitutive model for softening and damage rocks. Chinese Journal of Rock Mechanics and Engineering 17(6), 628-633. (In Chinese with English Abstract)

[8]. Cao, W.G., Zhao, H., Li, X., Zhang, Y.J., 2010. Statistical damage model with strain softening and hardening for rocks under the influence of voids and volume changes. Canadian Geotechnical Journal 47( 8), 857-871.

[9]. Cecconi, M., Viggiani, G.M., 2001. Structural features and mechanical behaviour of a pyroclastic weak rock. International Journal for Numerical and Analytical Methods in Geomechanics 25(15), 1525-1557.

[10]. Clayton, C.R.I., Serratrice, J.F., 1993. The mechanical properties and behaviour of hard soils and soft rocks. Proceedings of the International Symposium on Geotechnical Engineering of Hard Soils and Soft Rocks, Athens, Vol. 3, pp. 1839-1877.

[11]. Desai, C. S., 2005. Constitutive modeling for geologic materials: significance and directions. International Journal of Geomechanics 5(2), 81-84.

[12]. Desai, C.S., Faruque, M.O., 1984. Constitutive model for (geological) materials. Journal of Engineering Mechanics 110(9), 1391-1408.

[13]. Di Maio, C., Scaringi, G., Vassallo, R., 2014. Residual strength and creep behaviour on the slip surface of specimens of a landslide in marine origin clay shales: influence of pore fluid composition. Landslides 12(4), 657-667.

[14]. Frantziskonis, G., Desai, C. S., 1987. Constitutive model with strain softening. International Journal of Solids and Structures 23(6), 733-750.

[15]. Gens, A., Nova, R., 1993. Conceptual bases for a constitutive model for bonded soils and weak rocks. Proceedings of the International Symposium on Geotechnical Engineering of Hard Soils and Soft Rocks. Athens, Vol. 1, pp. 447-455.

[16]. Gens, A., Vaunat, J., Garitte, B., 2005. Elastoplastic modelling of hard soils and soft rocks: formulation and application. VIII Int. Conf. Computational Plasticity, COMPLAS VIII, Barcelona.

[17]. Hawkins, A.B., and Pinches, G.M., 1992. Engineering description of mudrocks. Quarterly Journal of Engineering Geology 25, 17-30.

[18]. Hornig, E.D., Klapperich, H., 2011. Laboratory tests and field measurements investigating the stress strain behaviour of foundations on hard soil and weak rock. Geotechnics of hard soils-weak rocks: Proceedings of the 15th European conference on soil mechanics and geotechnical engineering. Anagnostopoulos A, Pachakis M, Tsatsanifos C. (Eds.) IOS Press, 737-742.

[19]. Huang, S.B., Ji, S.W., Zhu, X.L.L., Li, H.Q., 2005. Analysis on Xigeda landslide in Xipan expressway. Journal of Highway and Transportation Research and Development (S1), 41-44. (In Chinese with English Abstract)

[20]. IAEG, 1979. Report of the commission on engineering geological mapping. Buletin IAEG 19, 364-371.

[21]. International Society for Rock Mechanics ISRM, 1982. Suggested Methods: Rock Characterization, Testing and Monitoring. Edited by Browm, E.T. Oxford.

[22]. Johnston, I.W., Novello, E.A., 1993. Soft rocks in the geotechnical spectrum, Geotechnical Engineering of Hard Soils - Soft Rocks (A. Anagnostopoulos et al., eds.) Balkema, Rotterdam. Vol.1: 177-183.

[23]. Kanji, M.A., 2014. Critical issues in soft rocks. Journal of Rock Mechanics and Geotechnical Engineering 6(3), 186-195. 
[24]. Kong, P., Granger, D.E., Wu, F.Y., Caffee, M.W., Wang, Y.J., Zhao, X.T., Zheng, Y., 2009. Cosmogenic nuclide burial ages and provenance of the Xigeda paleo-lake: Implications for evolution of the Middle Yangtze River. Earth and Planetary Science Letters 278, 131-141.

[25]. Krajcinovic, D., Silva, M.A.G., 1982. Statistical aspects of the continuous damage theory. International Journal of Solids and Structures 18(7), 551-562.

[26]. Lemaitre, J., 1984. How to use damage mechanics. Nuclear Engineering \& Design 80(2), 233-245.

[27]. Li, P., Liu, X.S., Yang, M.E., Yuan, J.L., 2012. Analysis of generation factors for tectonic deformation, in the Xigeda formation in southwestern China. Analysis of generation factors for tectonic deformation in the Xigeda formation in southwestern China. Engineering Sciences 10(1), 8-13.

[28]. Ling, S., Wu, X., Liao, X., Li, X., Zhao, S., 2015. Study on the water-rock interaction behavior of Xigeda strata in Lamaxi Gully, Sichuan Province, China. In: Lollino G. et al. (eds) Engineering Geology for Society and Territory - Volume 2. Springer, Cham 2107-2111.

[29]. Liu, H.J., Nie, D.X., 2004. A summary of the study of Xigeda Strata. Advance in Earth Science 19, 80-82. (In Chinese with English Abstract)

[30]. Luciano, P., 2015. Landslides in hard soils and weak rocks. Landslides 12(4), 641-641.

[31]. Margherita, Z., Claudio, C., Laura, E., Alessandrab, N., 2018. A risk assessment proposal for underground cavities in Hard Soils-Soft Rocks. International Journal of Rock Mechanics and Mining Sciences 103, 43-54.

[32]. Marinos, P.G., 1997. General report session 1: Hard soils-soft rocks: geological features with special emphasis to soft rocks, Geotechnical Engineering of Hard Soils - Soft Rocks (A. Anagnostopoulos et al., eds.), Balkema, Rotterdam. Vol. 3:1807-1826.

[33]. McCammon, N., 1999. Book review: The geotechnics of hard soils-soft rocks. Canadian Geotechnical Journal 36(6), 1206-1206.

[34]. Moon, V.G., 1993. Geotechnical characteristics of ignimbrite: A soft pyroclastic rock type. Engineering Geology 35(1-2), 33-48.

[35]. Quaternary Glacier Survey Group, 1977. Preliminary study on Xigeda formation in southwest China. In: Institute of Geomechanics, Chinese Academy of Geological Sciences ed, Collection on Quaternary Glacial Geology of China. Geological Publishing House, Beijing, pp. 144-154. (In Chinese)

[36]. Rotaru, A. 2011. Landslides triggered in hard soils and soft rocks in Romania. Geotechnics of hard soils-weak rocks: Proceedings of the 15th European conference on soil mechanics and geotechnical engineering. Anagnostopoulos A, Pachakis M, Tsatsanifos C. (Eds.) IOS Press, 1383-1388.

[37]. Shao, J.F., 1998. Poroelastic behaviour of brittle rock materials with anisotropic damage. Mechanics of Materials 30, 41-53.

[38]. Shen, Z.J., 1993. Elasto-plastic damage model of structural clay. Chinese Journal of Geotechnical Engineering 15(3), 21-28. (in Chinese with English Abstract)

[39]. Sitarenios, P., Bardanis, M., Kavvadas, M., 2011. Modelling the soil-water characteristic curve of structured and recomposed hard soils-weak rocks. Geotechnics of hard soils-weak rocks: Proceedings of the 15th European conference on soil mechanics and geotechnical engineering. Anagnostopoulos A, Pachakis M, Tsatsanifos C. (Eds.) IOS Press, 665-670.

[40]. Sun, Z.F., Qu, H.L., Wu, X.X., 2012. Research on the axial load transmission function of cast-in-place pile in Xigeda rock stratum. Advanced Materials Research 594-597, 612-615.

[41]. Tang, C.A., Hudson, J.A., Xu, X.H., 1993. Rock failure instability and related aspects of earthquake mechanisms. China Coal Industry Publishing House, Beijing, China.

[42]. Tatsuoka, F., Kohata, Y., 1995. Stiffness of hard soils and soft rocks in engineering applications. Proc. 1st Int. 
Symp. PreFailure Deformation Characteristics of Geomaterials, Sapporo 2, 947-1063.

[43]. Tommasi, P., Verrucci, L., Rotonda, T., 2014. Mechanical properties of a weak pyroclastic rock and their relationship with microstructure. Canadian Geotechnical Journal 52(2), 1-13.

[44]. Vaughan, P.R., 1993. Engineering behavior of weak rocks: some answers and some questions. Proceedings of the International Symposium on Geotechnical Engineering of Hard Soils and Soft Rocks, Athens, Vol. 3, pp. 1741-1765.

[45]. Vukadin, V., 2007. Modeling of the stress-strain behavior in hard soils and soft rocks. Acta Geotechnica Slovenica 2(2), 5-15.

[46]. Wang, W., Chen, W., Long, W., Die, J., 2018. Research and analysis on the landslide characteristics of Xigeda soil slope. American Institute of Physics Conference Series. American Institute of Physics Conference Series. AIP Conference Proceedings 1944, 020012.

[47]. Wen. L.N., Zhu, X.L., Bai, Z.Y., Zhou, K.X., You, Y., 2005. Rock and soil characteristics of Xigeda formation in Xinjiu area of expressway in west of Sichuan Province. Highway (7), 145-148. (In Chinese with English Abstract)

[48]. Xu, Z.M., 2011. Deposits of Zhaizi village landslide-dammed lake along Jinsha River and its implication for the genesis of Xigeda Formation. Geological Review 57(5), 675-686. (In Chinese with English Abstract)

[49]. Xu, Z.M., Liu, W.L., 2011. Some problems in the study of the genesis of Xigeda Formation. Earth Science Frontiers 18(5), 256-270. (In Chinese with English Abstract)

[50]. Yang, S.H, Su, L.J., Zhang, C.L., Li, C., Hu, B.L., 2020. Analysis of seepage characteristics and stability of Xigeda Formation slope under heavy rainfall. Journal of Civil and Environmental Engineering. http://kns.cnki.net/kcms/detail/50.1218.TU.20200224.1823.004.html. (In Chinese with English Abstract)

[51]. Yuan, F.L., 1958. Some stratigraphical material from southwestern area, China. Quaternaria Sinica 1(2), 130140. (In Chinese)

[52]. Zhang, S., 2009. Geological formation names of China (1866-2000). Springer. pp. 1250.

[53]. Zhang, W., Xu, Z.M., Liu, W.L., Li, L., 2011. Study on the influence of water content to shear strength of Xigeda-strata clay rock in Xichang. Geotechnical Investigation \& Surveying 39 (5), 1-5. (In Chinese with English Abstract)

[54]. Zhou, H., Cao, P., Zhang, K., 2014. In-situ direct shear test on Xigeda Formation clay stone and siltstone. Journal of Central South University (Science and Technology) (10), 3544-3550. (In Chinese with English Abstract)

[55]. Zhou, P., Wang, Z.J., Xu, H.Y., Zhao, Q.C., Sun, C.S., 2017. Stability and sub-classification study on the tunnel surrounding rock of Xigeda strata considering the influence of moisture content. China Civil Engineering Journal 50(12), 97-110. (In Chinese with English Abstract) 


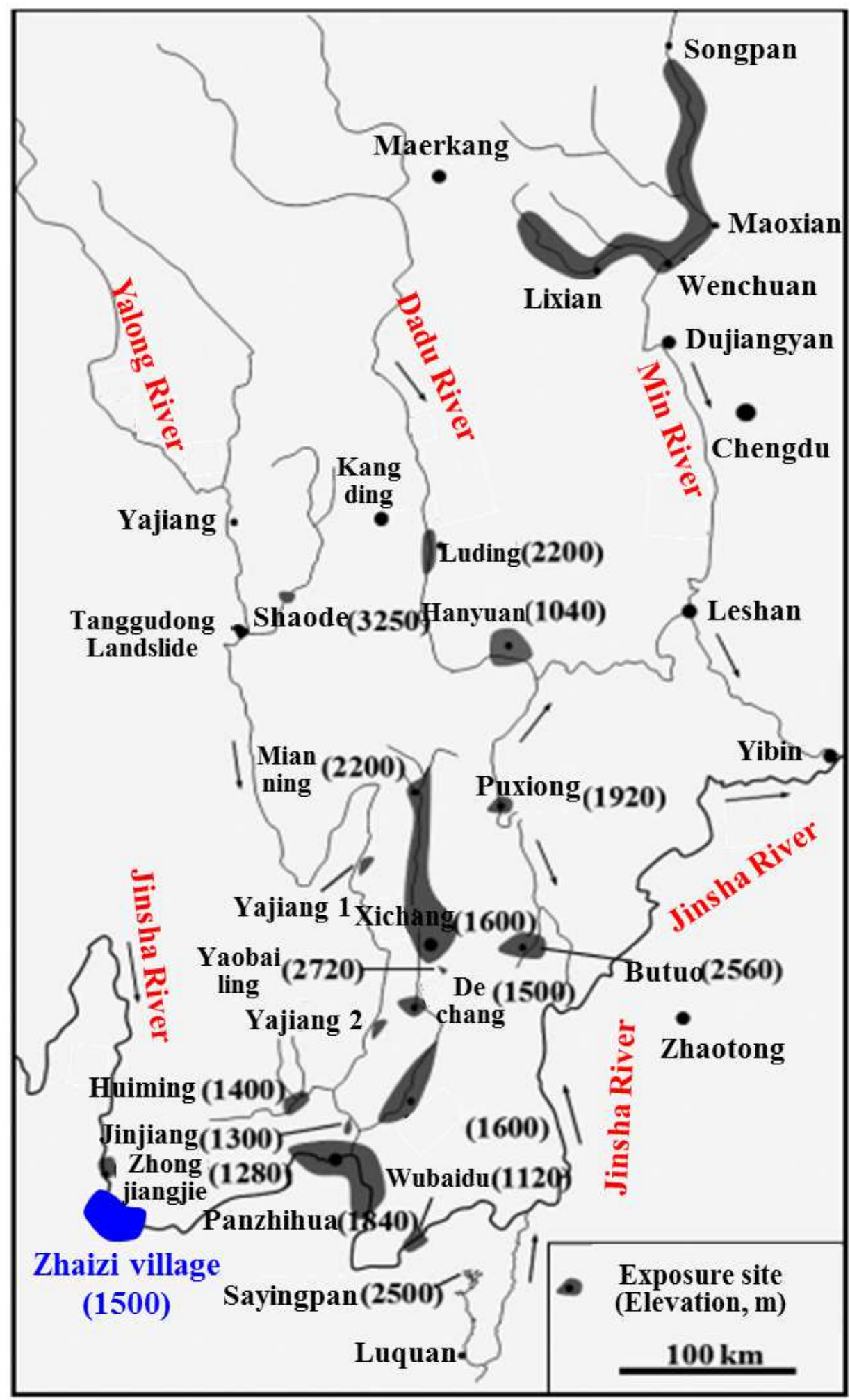

Figure 1

Distribution of the Xigeda formation. Modified from Xu and Liu (2011). Note: The designations employed and the presentation of the material on this map do not imply the expression of any opinion whatsoever on the part of Research Square concerning the legal status of any country, territory, city or area o bbnhjr 
of its authorities, or concerning the delimitation of its frontiers or boundaries. This map has been provided by the authors.
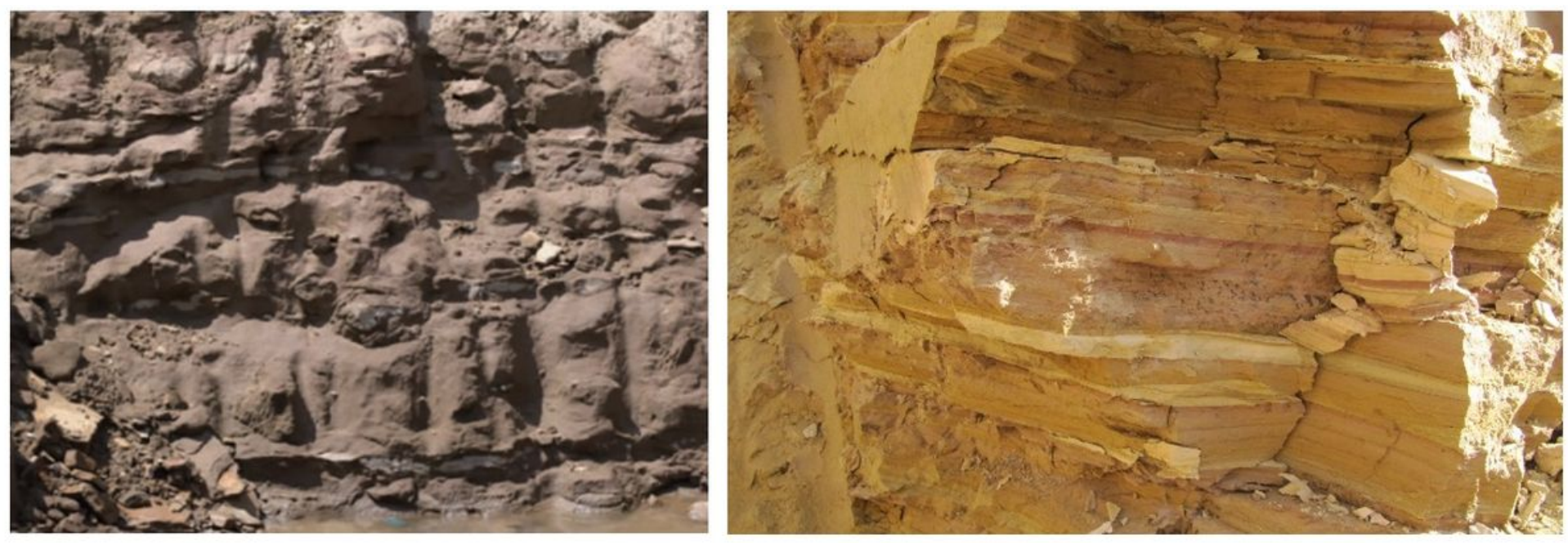

(a) Jingjiu Twonship of Sichuan Province (Xu, 2011)

(b) Zhaizi village of Yunnan Province

\section{Figure 2}

Structural characteristics of the Xigeda formation. 


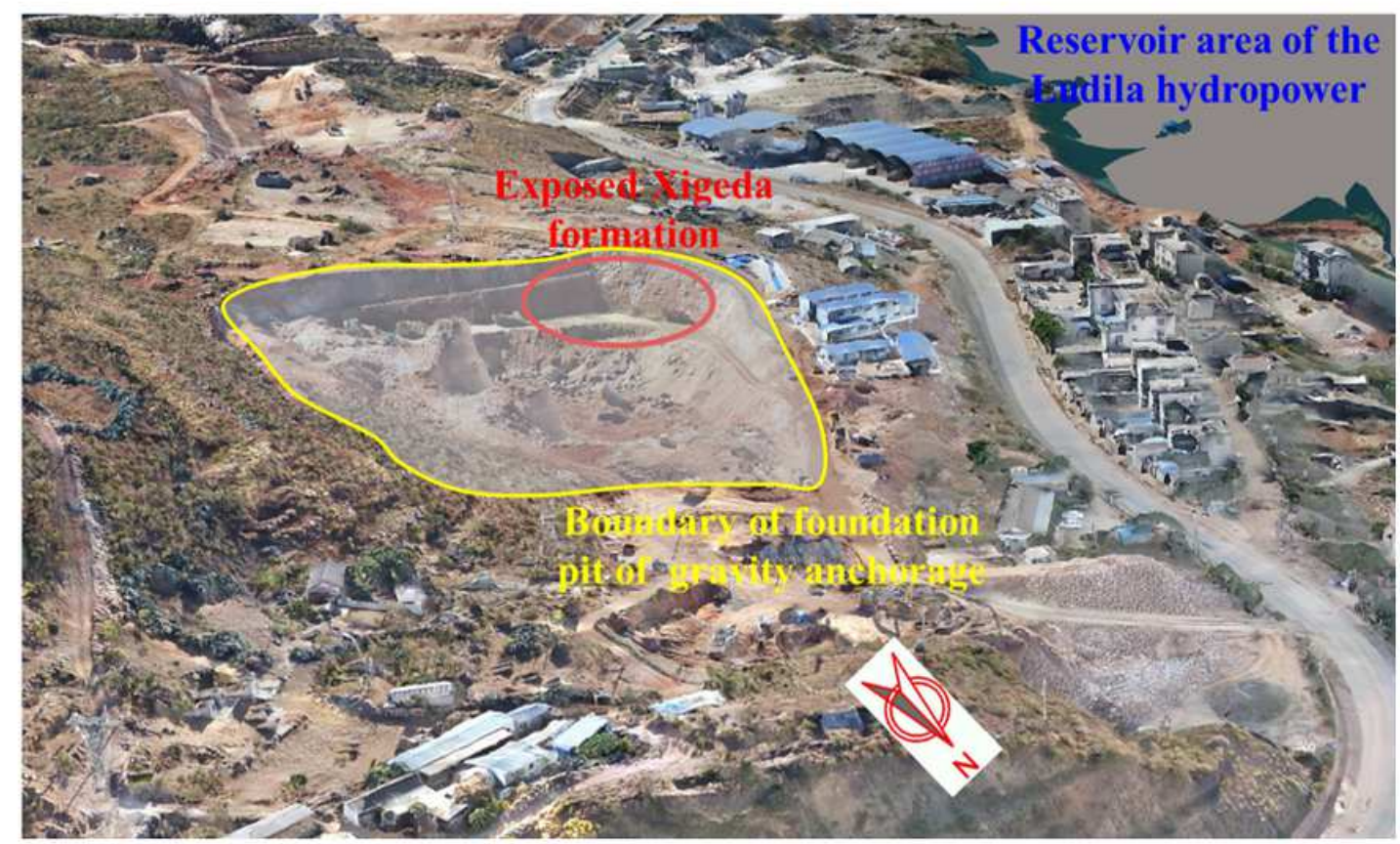

(a) The site photographed by a drone

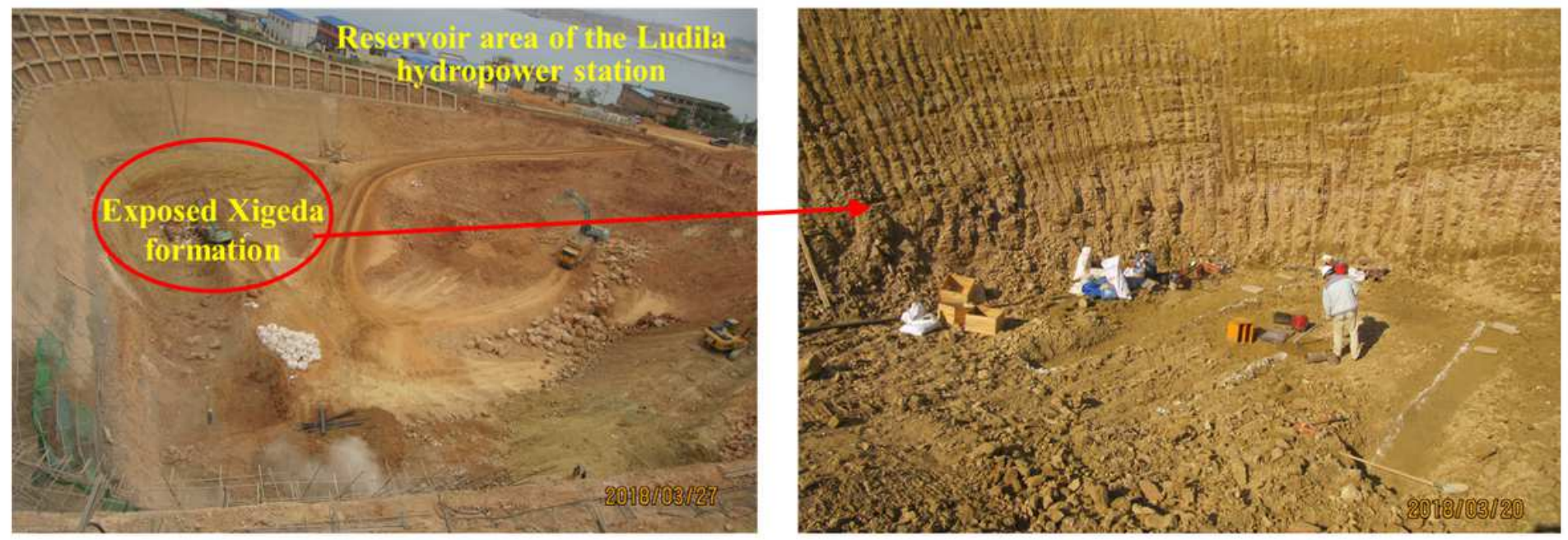

(b) Field sampling

\section{Figure 3}

Field investigation and sampling of the Xigeda formation exposed in a foundation pit. 


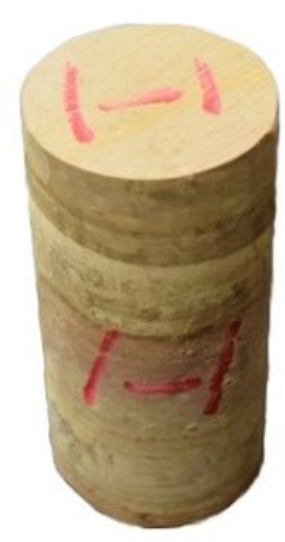

(a) $17.79 \%$

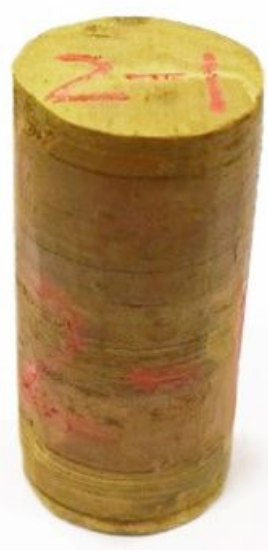

(b) $20.58 \%$

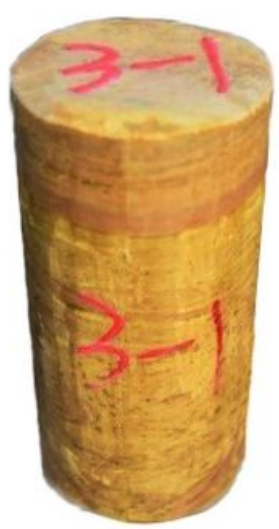

(c) $24.86 \%$

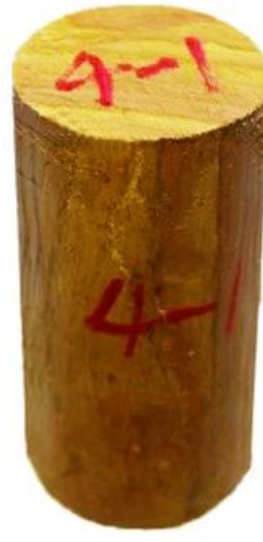

(d) $26.52 \%$

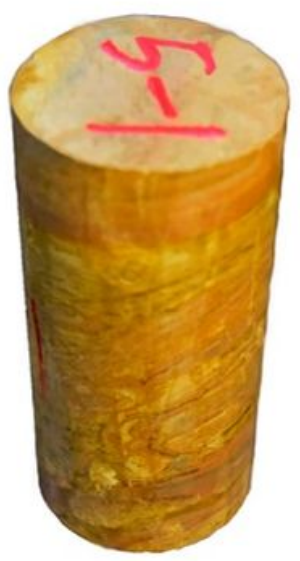

(e) $30.83 \%$

\section{Figure 4}

Samples with different water contents for triaxial compression testing.

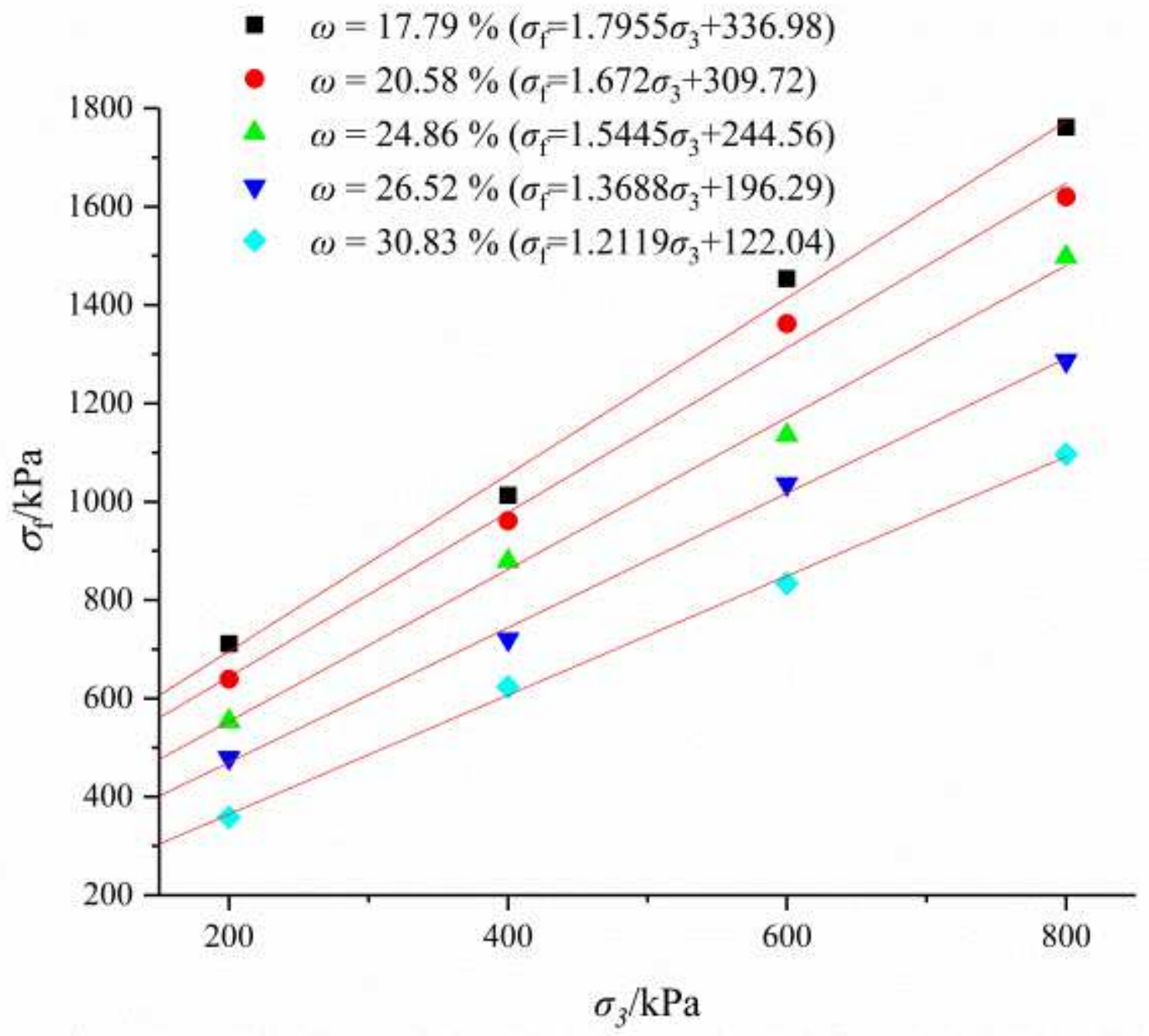

Figure 5 
Relationship between peak strength and confining pressure.

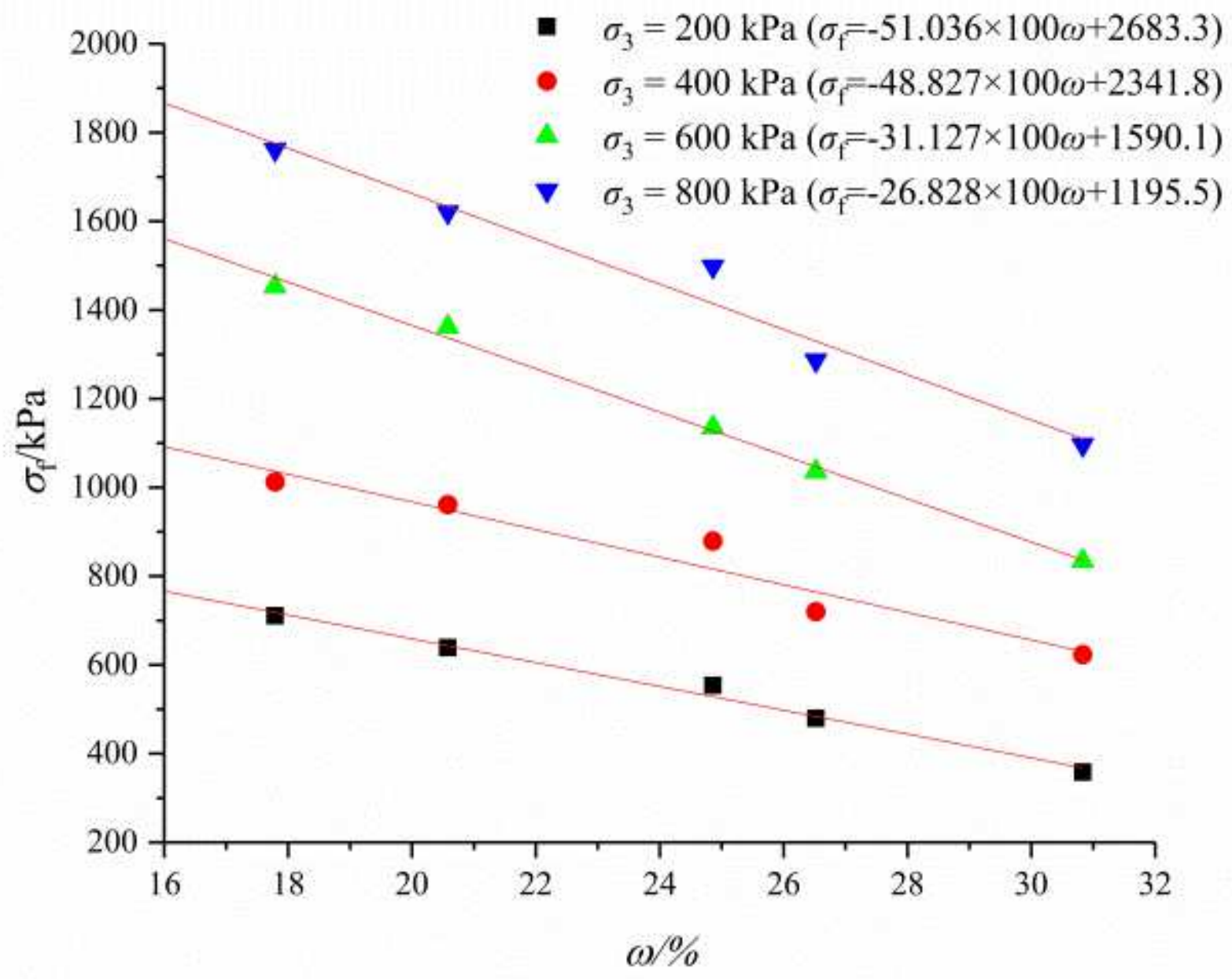

Figure 6

Relationship between peak strength and water content. 


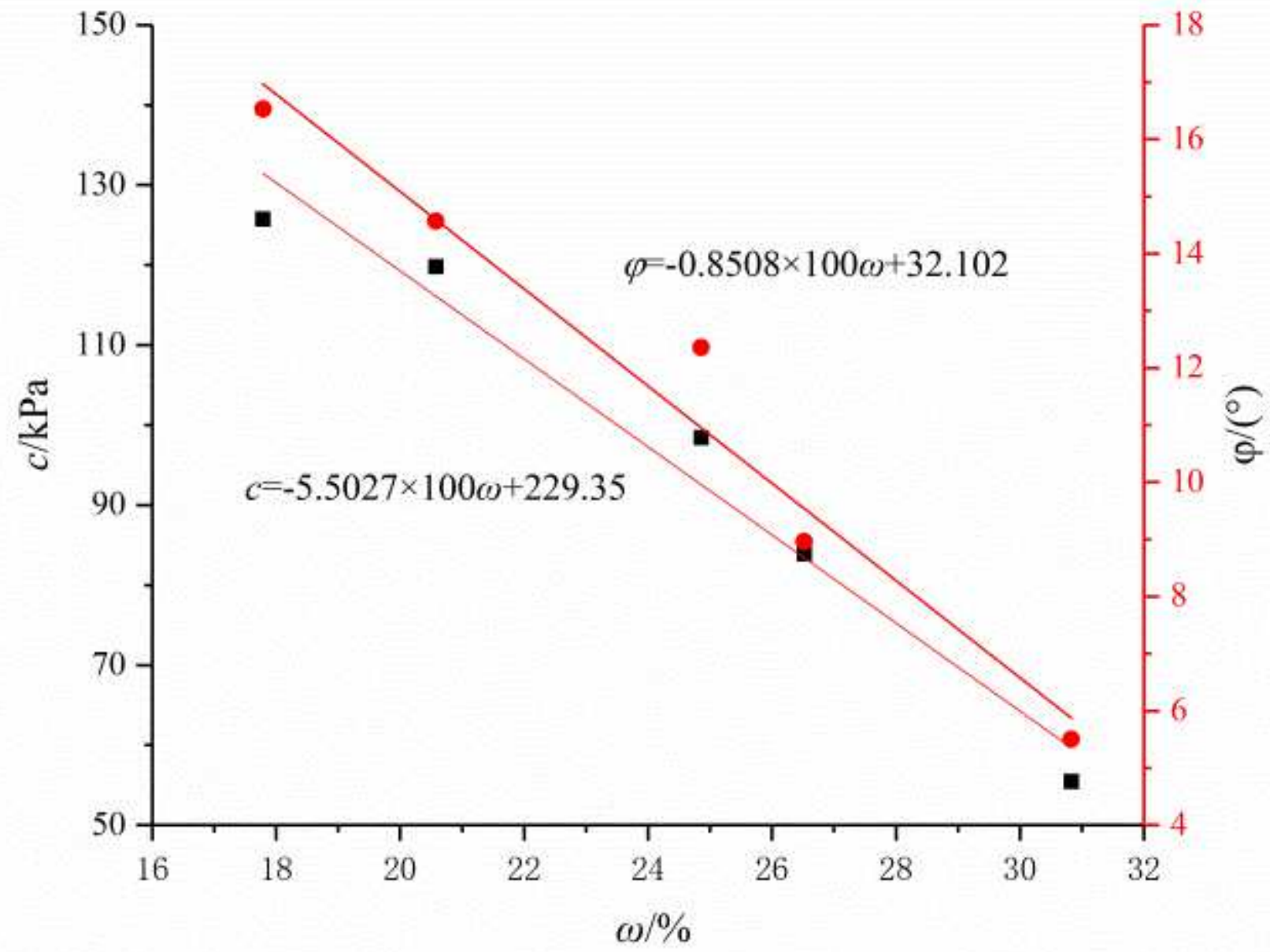

Figure 7

Relationship between cohesion, friction angle, and water content. 


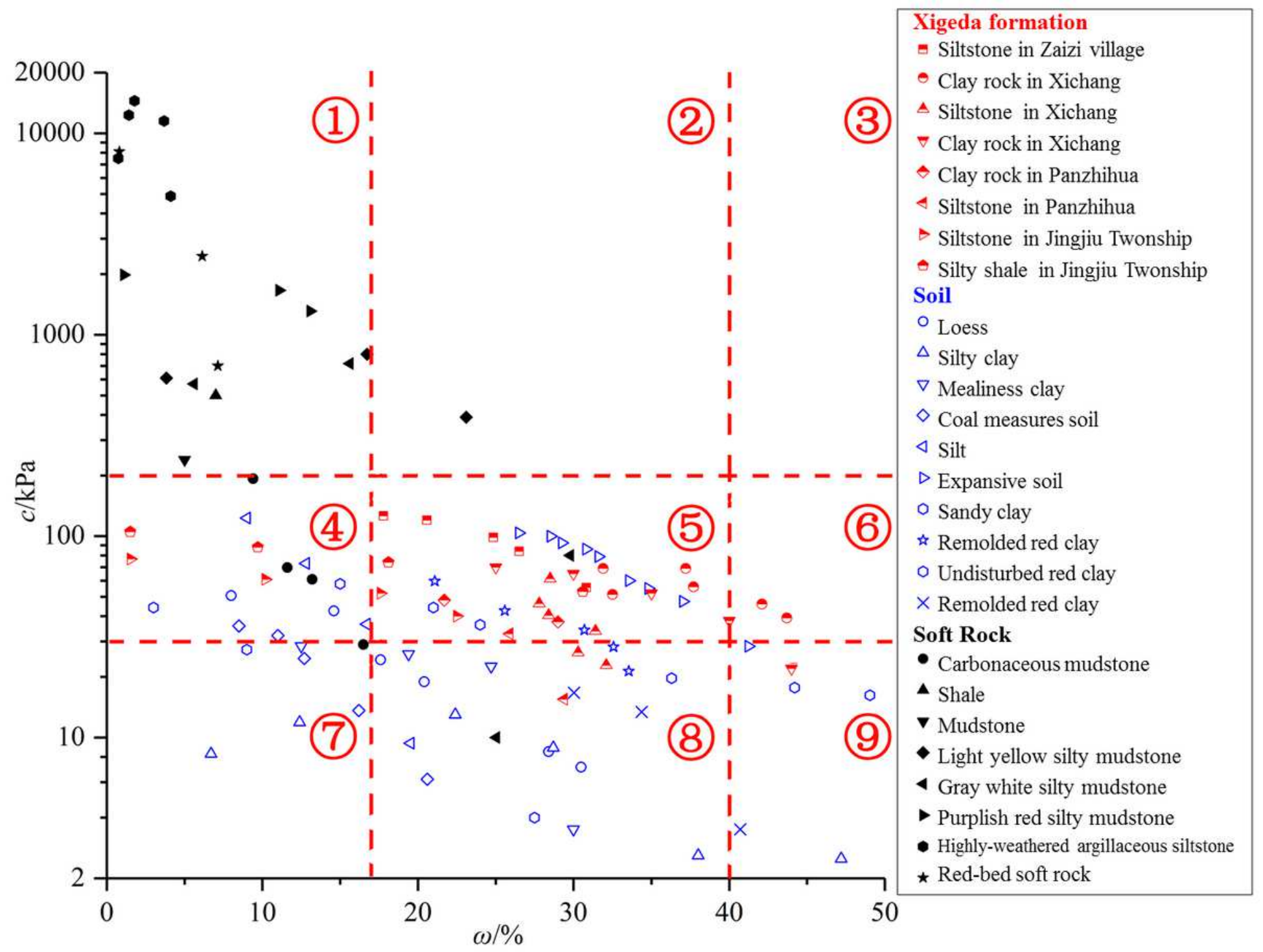

Figure 8

Relationship between cohesion and water content: the Xigeda formation, soil. and soft rock. 


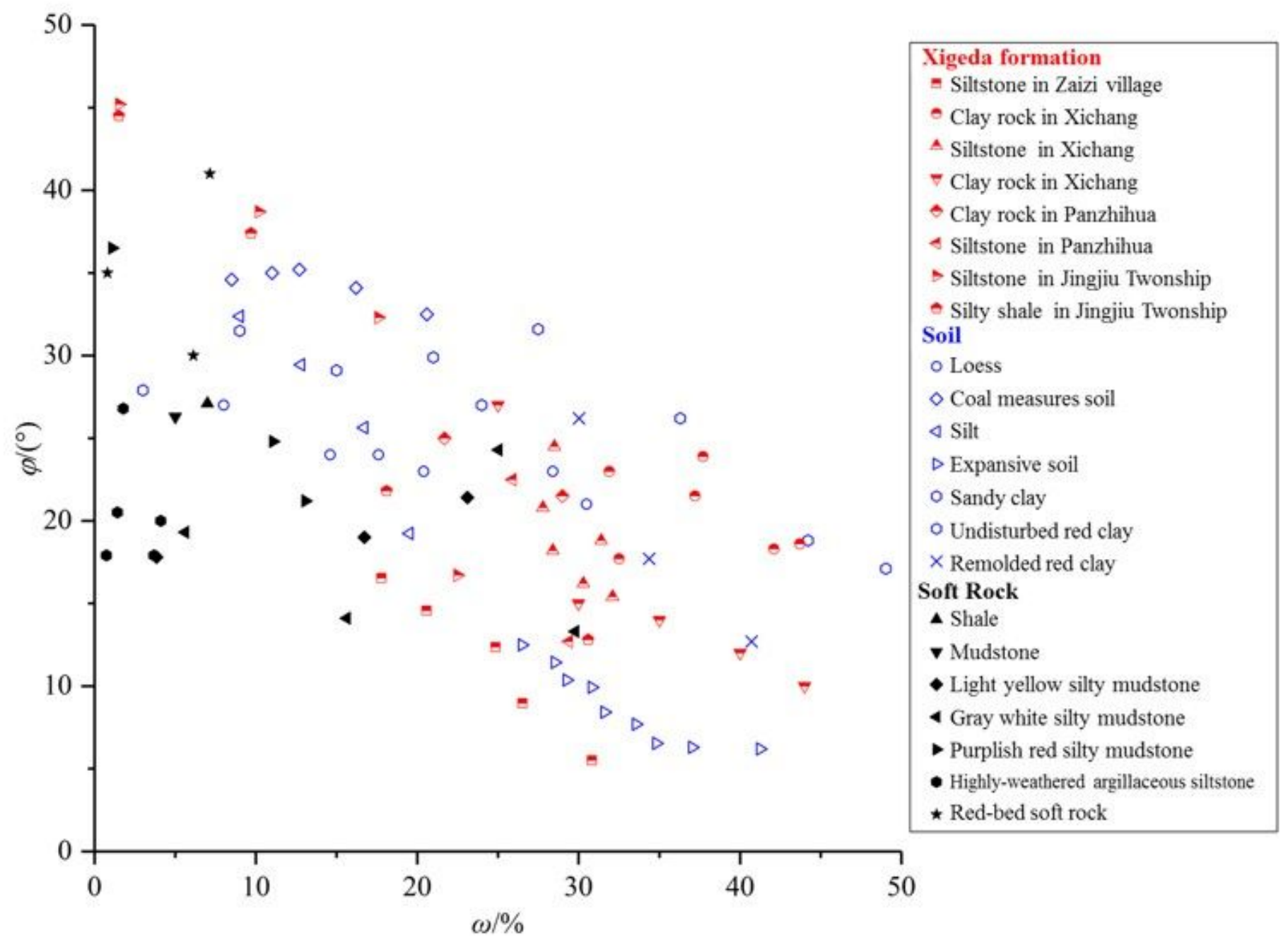

Figure 9

Relationship between friction angle and water content: the Xigeda formation, soil, and soft rock. 


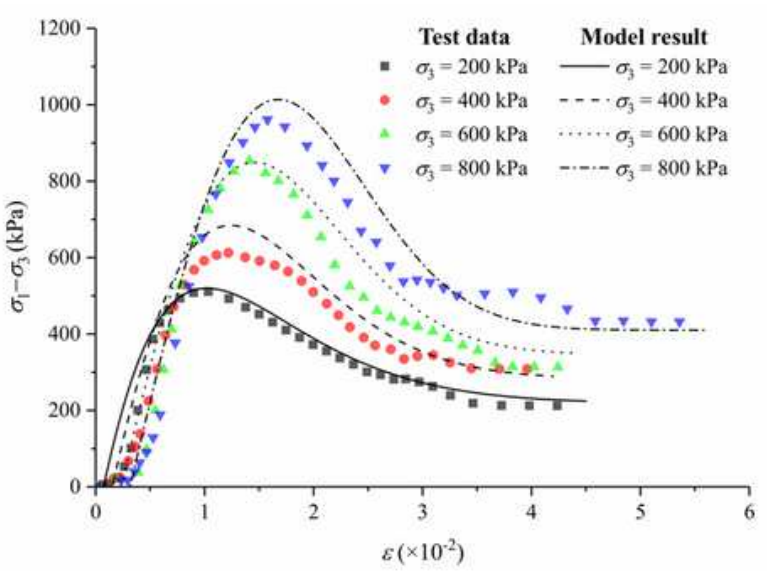

(a) $\omega=17.79 \%$

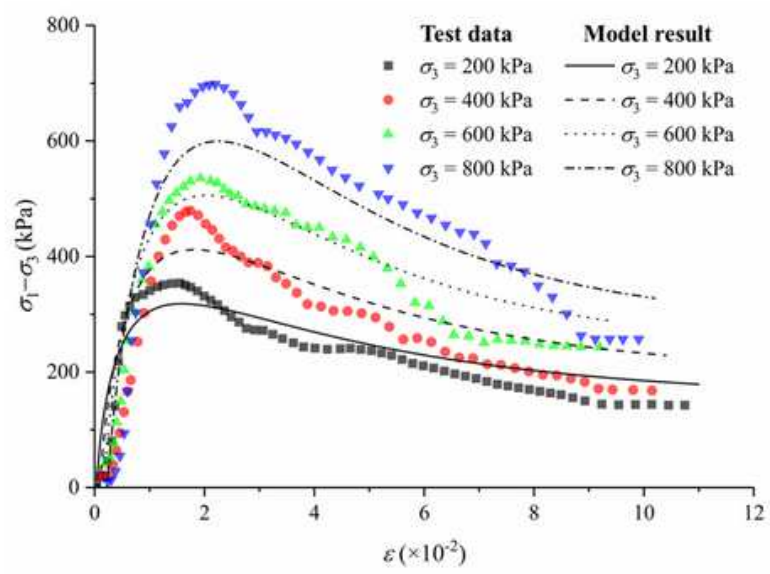

(c) $\omega=24.86 \%$

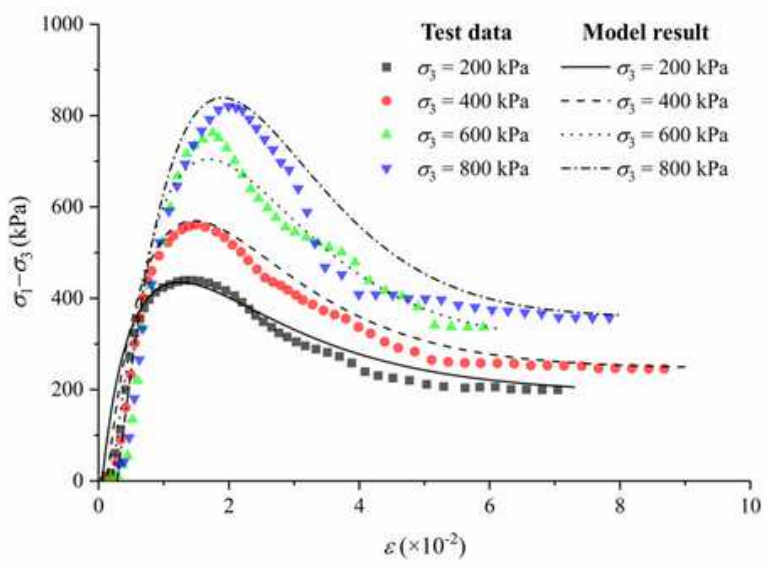

(b) $\omega=20.58 \%$

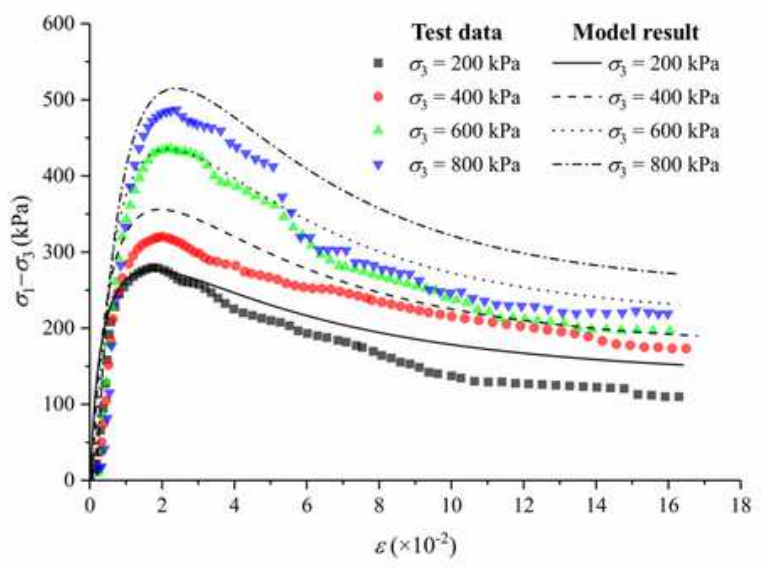

(d) $\omega=26.52 \%$

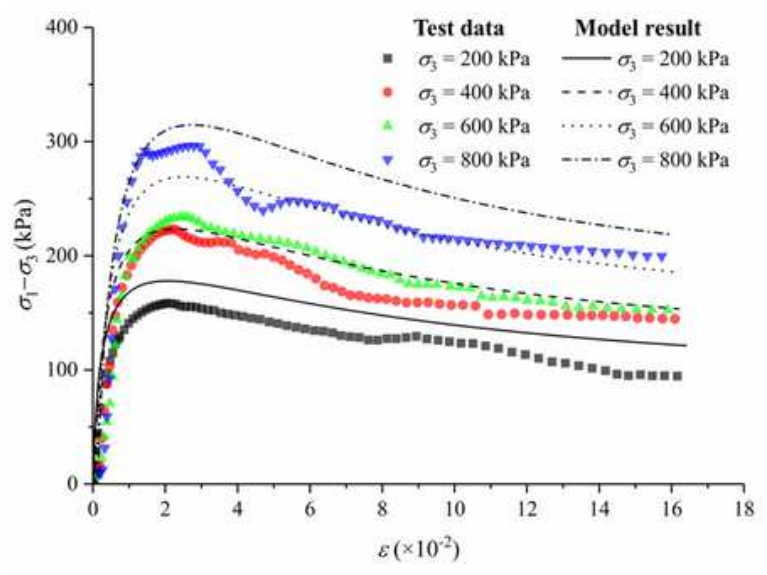

(e) $\omega=30.83 \%$

\section{Figure 10}

Comparisons of test data and model results at different water contents. 


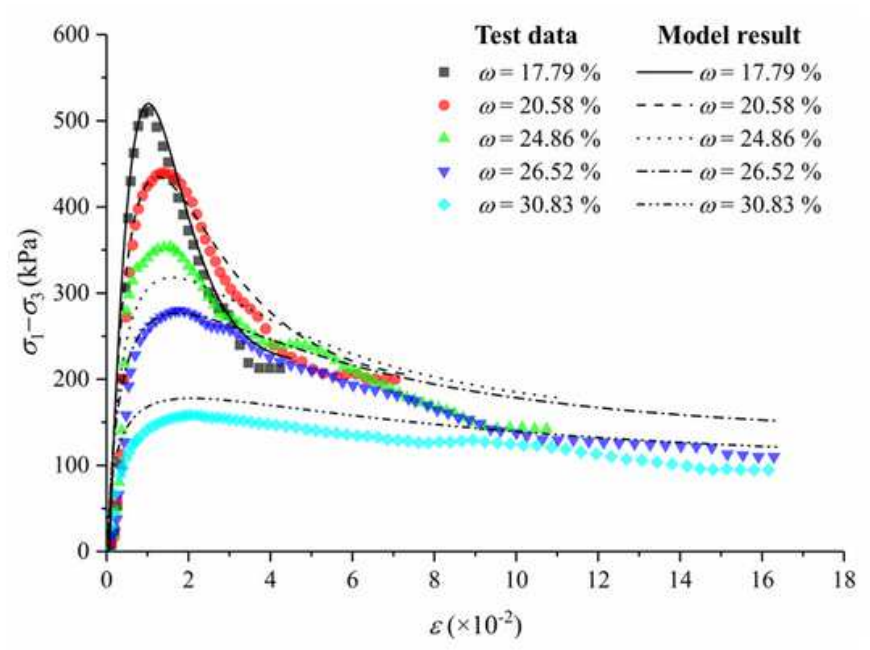

(a) $\sigma_{3}=200 \mathrm{kPa}$

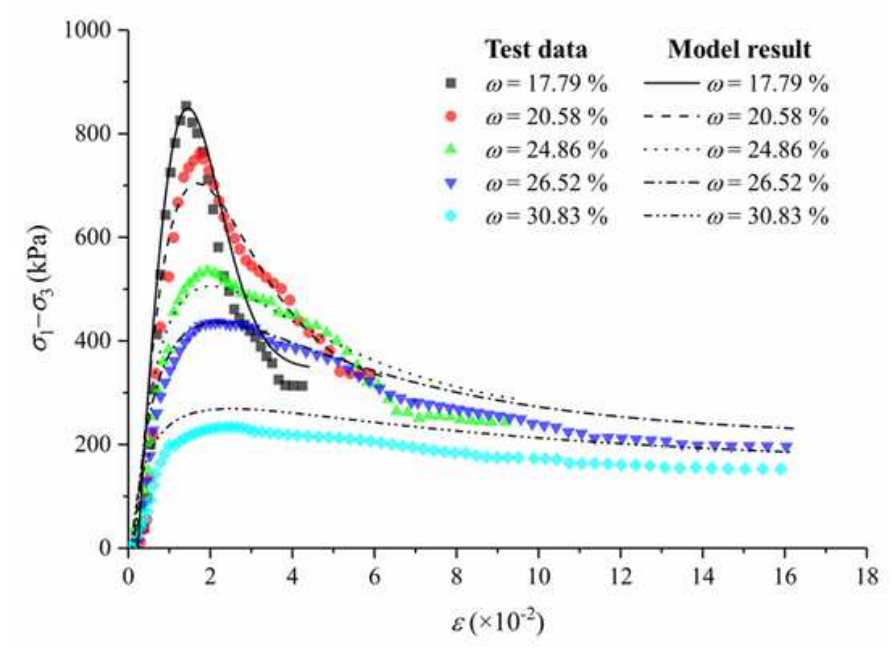

(c) $\sigma_{3}=600 \mathrm{kPa}$

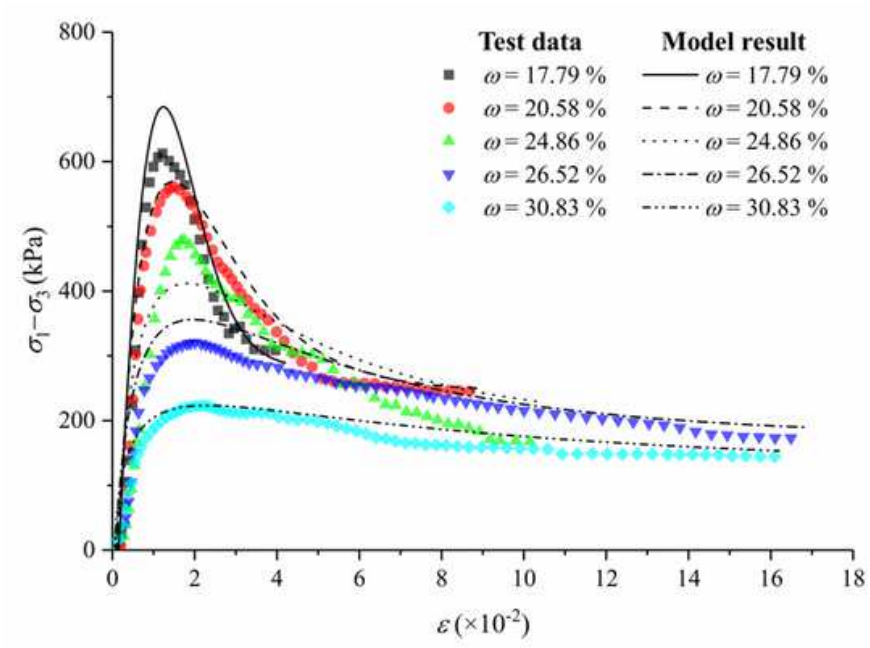

(b) $\sigma_{3}=400 \mathrm{kPa}$

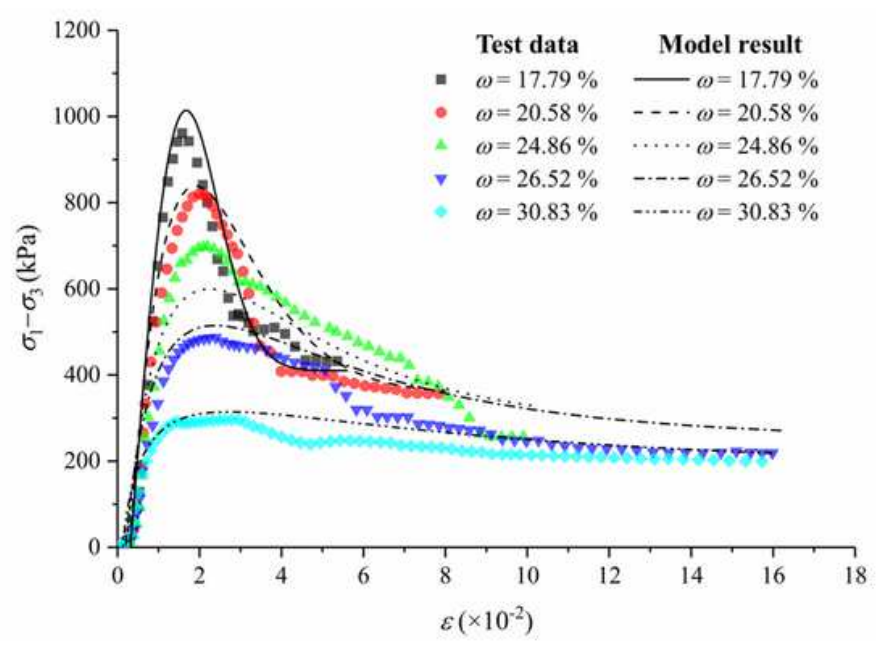

(d) $\sigma_{3}=800 \mathrm{kPa}$

\section{Figure 11}

Comparisons of test data and model results at different confining pressures. 